\title{
Castrum Novum (Santa Marinella, prov. de Rome)
}

Chronique de la campagne de septembre 2013

Flavio Enei, Marie-Laurence Haack, Sara Nardi-Combescure, Grégoire Poccardi, Luca Desibio, Massimiliano Galletti, Alessandra Squaglia et David Vattier

\section{(2) OpenEdition \\ 12 Journals}

Édition électronique

URL : http://journals.openedition.org/cefr/1188

DOI : $10.4000 /$ cefr. 1188

ISSN : 2282-5703

Éditeur

École française de Rome

Référence électronique

Flavio Enei, Marie-Laurence Haack, Sara Nardi-Combescure, Grégoire Poccardi, Luca Desibio, Massimiliano Galletti, Alessandra Squaglia et David Vattier, « Castrum Novum (Santa Marinella, prov. de Rome) », Chronique des activités archéologiques de l'École française de Rome [En ligne], Italie centrale, mis en ligne le 15 mai 2014, consulté le 31 octobre 2019. URL : http://journals.openedition.org/cefr/ 1188 ; DOl : 10.4000/cefr. 1188

Ce document a été généré automatiquement le 31 octobre 2019

(c) École française de Rome 


\section{Castrum Novum (Santa Marinella, prov. de Rome)}

Chronique de la campagne de septembre 2013

Flavio Enei, Marie-Laurence Haack, Sara Nardi-Combescure, Grégoire Poccardi, Luca Desibio, Massimiliano Galletti, Alessandra Squaglia et David Vattier

Zona A, settore 1 : il balneum de « le Guardiole ». Lo scavo

\section{(Sara Nardi-Combescure e David Vattier)}

Con il toponimo «le Guardiole » si distingue un'area, situata in corrispondenza del $\mathrm{km} 64,4$ della via Aurelia, a circa $200 \mathrm{~m}$ in direzione nord dell'area del «casale Alibrandi », dove è stato localizzato l'abitato di Castrum Novum (fig. 1). 
Fig. 1 - Castrum Novum. L'area de " Le Guardiole », prima dello sviluppo urbanistico degli anni 1960 e 1970 .

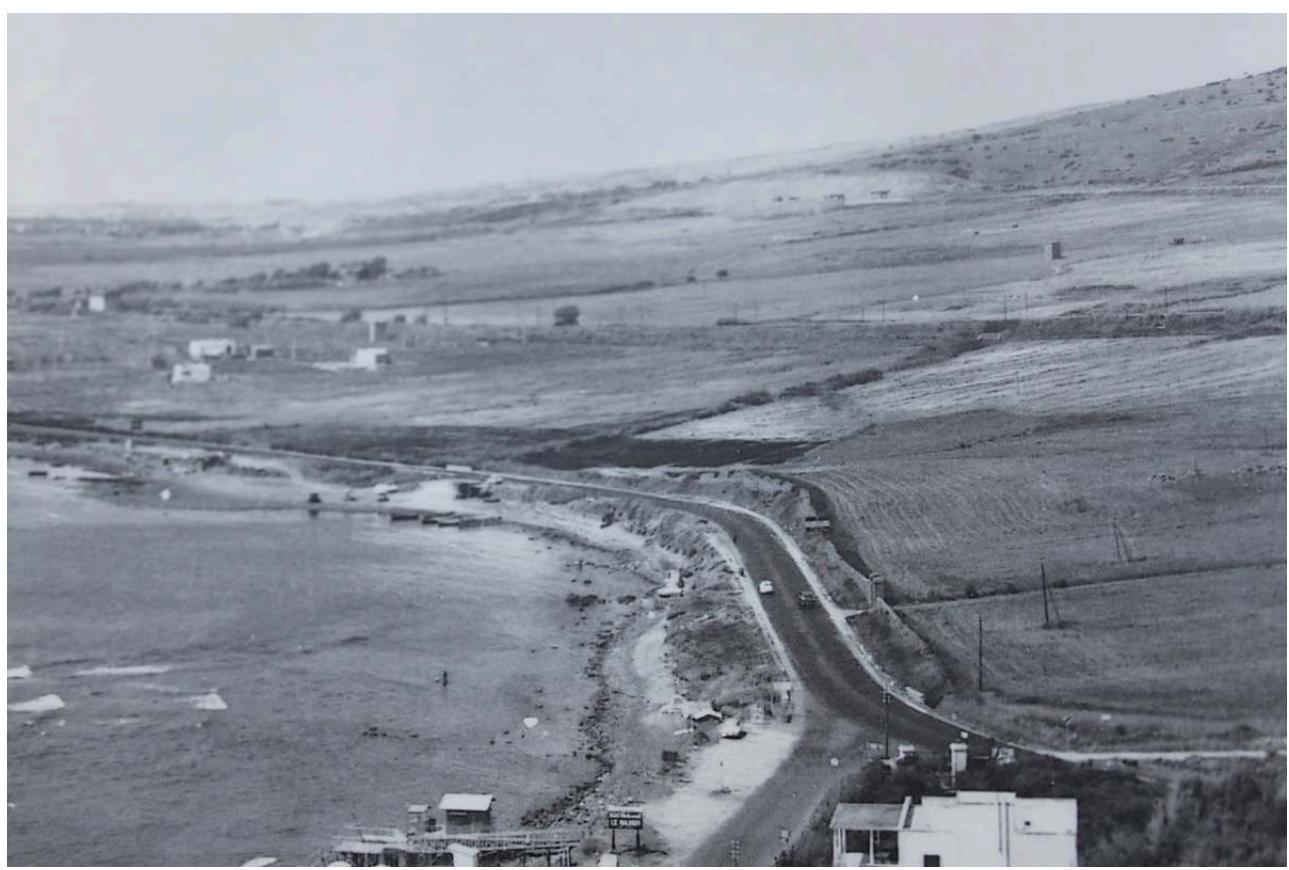

DA BIANCHI - GIACOMELLI, P. 77.

2 Stando a G. Dennis, il toponimo sarebbe derivato dalla presenza di sepolture etrusche nella località vicina « Pontone del Castrato », riutilizzate poi come postazioni di guardia per militari ${ }^{1}$. È probabile che il nome sia piuttosto riferibile alla presenza in prossimità di "Torre Chiaruccia", che doveva costituire uno dei principali baluardi per il controllo di questo tratto della costa tirrenica, a partire del secolo XVI, oppure alla presenza dei resti di una struttura che potrebbe essere datata ad epoca posteriore l'abbandono del balneum ${ }^{2}$. Nel Catasto Alessandrino (1660) e nel Catasto Rustico della Provincia di Roma (secolo XIX), quest'area è compresa nella tenuta di Santa Marinella ${ }^{3}$.

Una prima campagna di scavo sul balneum è stata effettuata nel 1970, sotto la direzione di G. Colonna, allora ispettore della Soprintentendenza Archeologica per l'Etruria Meridionale, durante la quale sono stati messi in luce una serie di ambienti, ascrivibili tra la fine del I secolo a. C. e i primi decenni del II secolo d. C. ${ }^{4}$ (fig. 2). 
Fig. 2 - Castrum Novum. Planimetria del balneum de « Le Guardiole ».

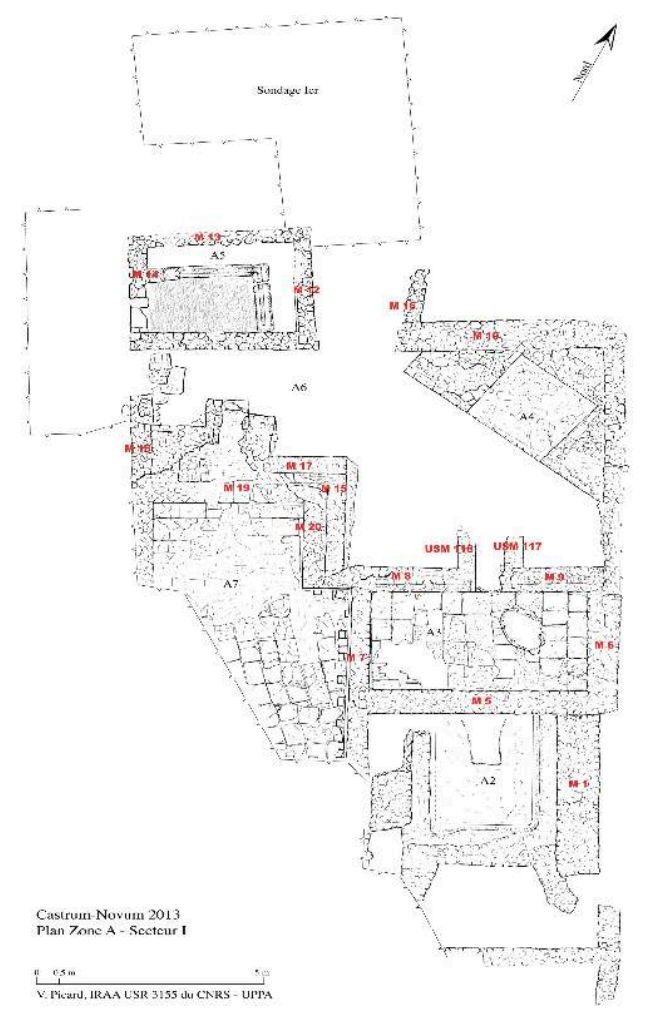

V. PICARD (IRAA).

Fra essi si ricordano :

- un ambiente (Ambiente 2) coperto da un pavimento in mosaico e con una vasca, fiancheggiata da un canale,

- un tepidarium (Ambiente 3) con tracce di suspensurae nell'ipocausto,

- due praefurnia (uno all'esterno dell'ambiente 3 e l'altro situato nell'Ambiente 6),

- un caldarium con tubuli in terracotta, inseriti nelle pareti (Ambiente 7),

- e infine una forica (Ambiente 5) con pavimento in opus spicatum ${ }^{5}$.

5 Fra i materiali più interessanti raccolti all'epoca si segnalano due bolli rettangolari, portanti iscrizioni C. Nevi [Philomus(i)] e C. Calvi Fi[dentis] ${ }^{6}$, una corniola con rappresentati Faustolo, Romolo e Remo, datata alla metà del II d. C.7 ed oggi conservata nel Museo nazionale di Civitavecchia ed infine numerosi frammenti di ceramica sigillata tardo-italica, alcuni dei quali con bolli sul fondo ${ }^{8}$.

6 Le campagne di ricerca condotte negli anni 2010-2012, sono state consacrate principalmente alla rilettura stratigrafica delle strutture murarie del balneum e all'apertura di un nuovo sondaggio (sondaggio I), all'esterno alle aree indagate precedentemente, dal quale sembrano affiorare fasi di crollo associate a una trincea di spoliazione.

7 È nel corso del mese di settembre che l'area scavata, che misura ormai circa $20 \times 30$ metri, ha permesso di arricchire il dossier archeologico del balneum di nuovi elementi9. 


\section{Ambiente 2}

8 All'interno dell'Ambiente 2, identificato come frigidarium che si estende sui lati nord est-sud ovest fra i muri 5 e 25 è stata scavata una piccola fossa di spoliazione (US 115) di forma allungata, situata nella vasca rettangolare a ridosso del muro 5 e già visibile nella pianta realizzata alla fine degli scavi degli anni 1970 (fig. 3).

Fig. 3 - Castrum Novum. La fossa US 115.

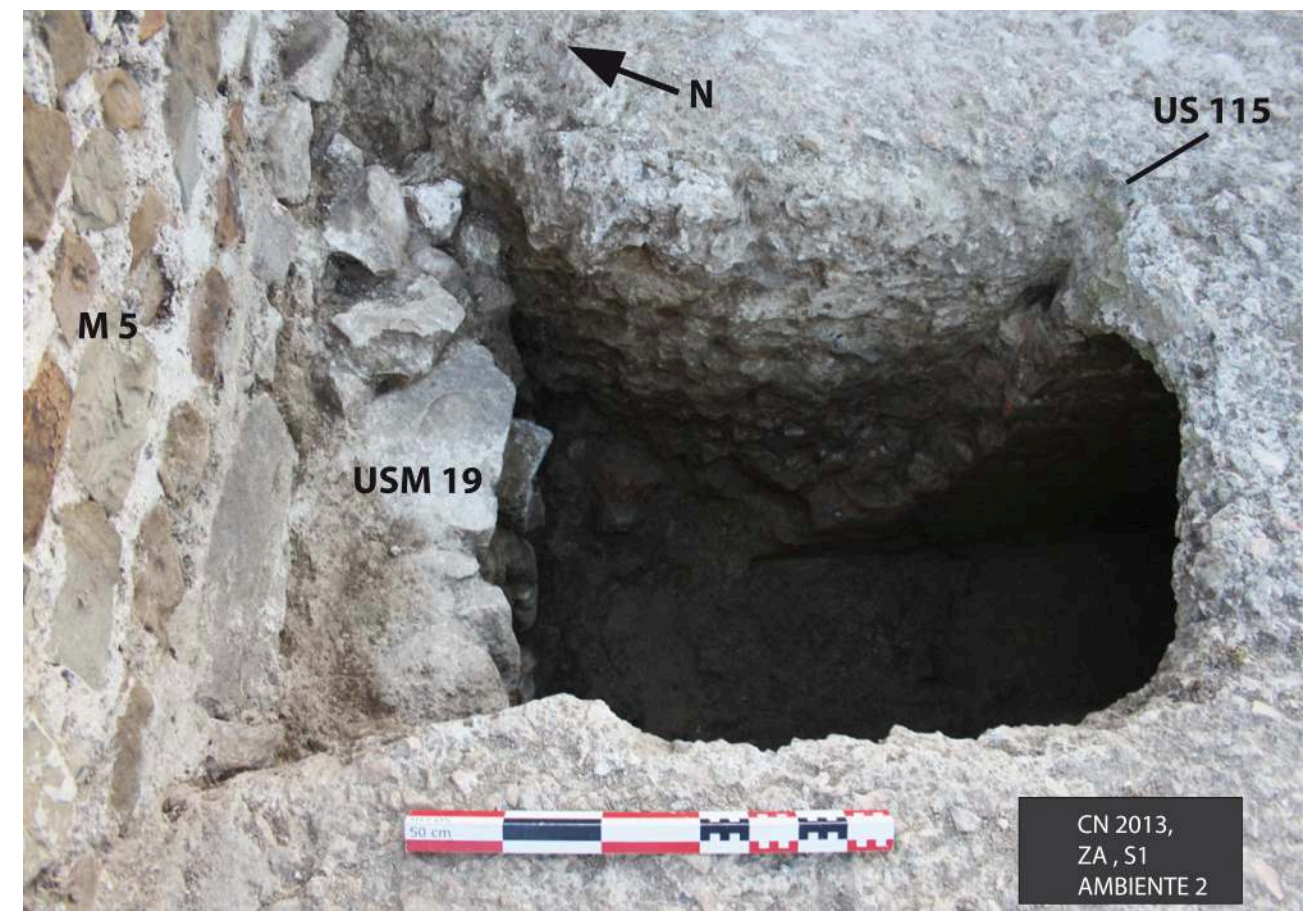

S. NARDI-COMBESCURE.

La fossa ha intaccato una fogna (Canale1) che attraversa in senso nord est-sud ovest gli Ambienti 2 e 3 e il cui riempimento presentava numerosi frammenti dei mattoni, provenienti dal paramento delle spallette in laterizio del canale. All'interno dello strato di riempimento (US 116) non è stato trovato alcun materiale moderno, cosa che lascia pensare che la fossa sia stata praticata poco dopo l'abbandono del balneum, per il recupero di un tombino (forse marmoreo), dal quale defluivano le acque della vasca.

10 Nel settore meridionale del frigidarium, a circa 15 centimetri di profondità del piano di calpestio attuale è stato evidenziato uno strato (US 123), caratterizzato dalla presenza di grossi blocchi tagliati, disposti volontariamente l'uno contro l'altro, con scarsa ceramica ma numerose tessere musive bianche e nere. Si tratta molto probabilmente di un vespaio pavimentale che doveva essere coperto da un mosaico in bianco e nero al quale accenna già P.A. Gianfrotta ${ }^{10}$. Esempi di mosaici bicromi sono ampiamenti attestati in quest'area come l'esemplare pubblicato da Salvatore Bastianelli, proveniente da un ambiente con suspensurae ${ }^{11}$ situato lungo la costa o quelli che coprivano un altro spazio con suspensurae relativo alla domus a atrium del settore $2^{12}$.

11 Va segnalato che nella parte sud del frigidarium, all'interno dello strato di humus ampiamente inquinato da materiale moderno, è stato ritrovato un frammento di 
mattone con bollo che rimanda alle figline di Claudius Alexandrus, delle quali si conosce un altro esemplare proveniente dall'area urbana di Castrum Novum ${ }^{13}$.

La fogna (Canale 1, fig. 4) sembra essere conservata per una lunghezza di circa 5 metri e la sua costruzione potrebbe essere ascrivibile a una delle fasi più antiche del balneum, anteriore alla ristrutturazione del tepidarium dell'ambiente 3 e del frigidarium dell'Ambiente 2. È in questa occasione e in un'epoca ancora imprecisata, che essa viene in parte obliterata dalla costruzione dell'ipocausto dell'Ambiente 3 (del quale fa parte il muro 5) mentre viene ancora utilizzata per il deflusso delle acque della vasca del frigidarium dell'Ambiente 2.

Fig. 4 - Castrum Novum. II Canale 1.

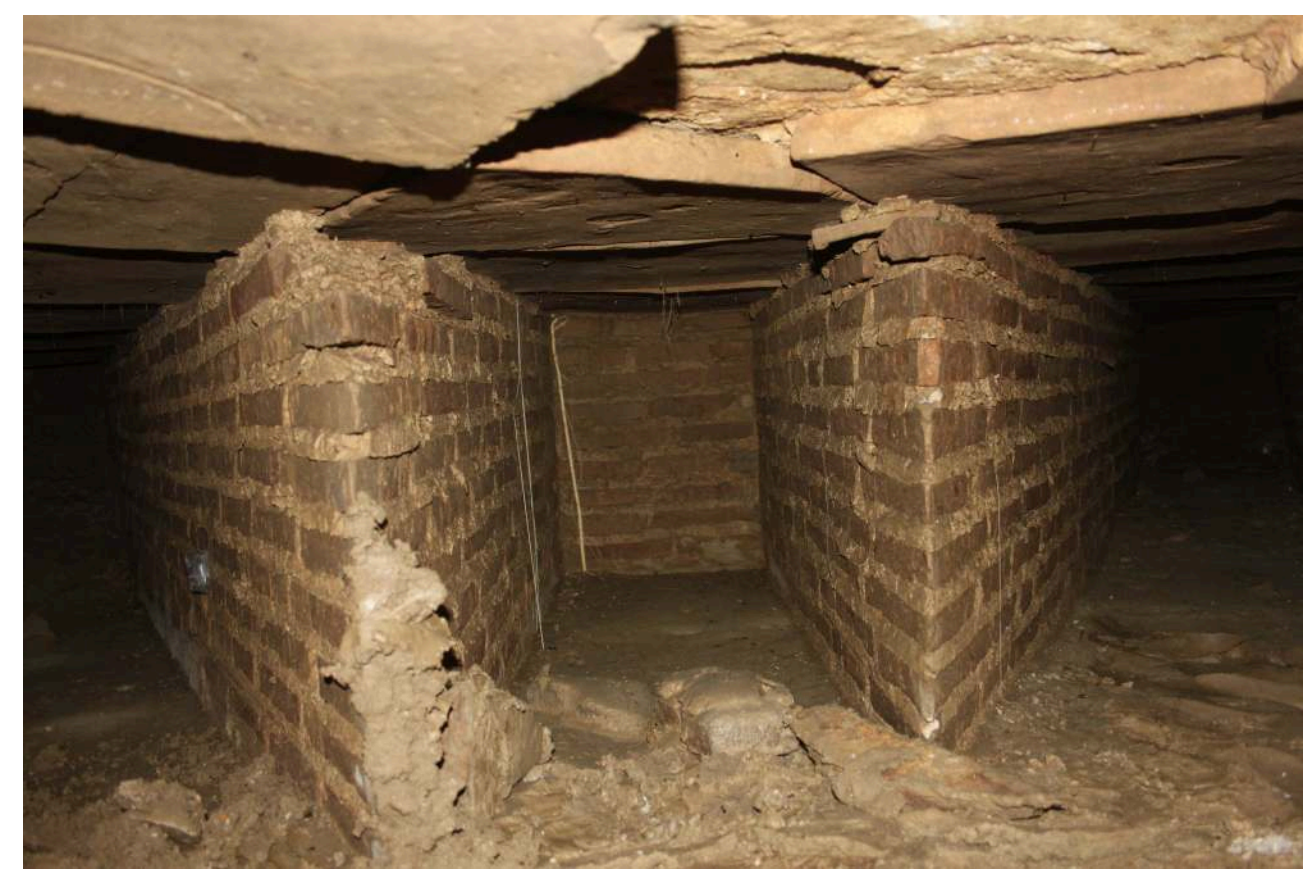

M. LEROY.

13 Nonostante lo stato di conservazione sia buono, per ragioni di sicurezza si è preferito limitare la documentazione ad alcume immagini fotografiche. Da esse si deduce che dal canale principale, allineato in senso nord est-sud ovest, all'altezza del frigidarium partivano due diramazioni, di cui una diretta verso il mare a ovest e l'altra diretta a est verso il fosso de « le Guardiole ». Dal punto di vista formale il paramento delle spallette (USM 20 e 21) è in mattoni triangolari, disposti a filari orizzontali (modulo 5 letti di malta e 5 filari di mattoni $=31$ centimetri), con letti di malta che variano dai 3 ai 4 centimetri di spessore.

14 Il pavimento si compone di una sequenza di bipedali, visibile all'interno della fossa US 115, in uno dei quali è appena visibile un bollo rettangolare non leggibile, situato ai piedi dell'USM 21, a circa $50 \mathrm{~cm}$ in direzione est dall'USM 19 (fondazione del muro 5). I bipedali sono coperti da uno stratino di malda dura, formatosi a seguito della distruzione delle spallette del Canale 1.

15 È interessante notare che nel tetto del canale, anch'esso composto da bipedali sono visibili due bolli laterizi con iscrizione $\mathrm{Cn}(e i)$ Domiti. Aprilis, dei quali si conoscosce un altro esemplare proveniente dagli scavi effettuati da D. Annovazzi alla «Chiaruccia $»^{14}$. 


\section{Area prospiciente l'ambiente 3} calpestio relativo alla fine degli scavi degli anni 1970 (US 111) che copriva due strati non intaccati dalle indagini precedenti, i quali presentano le stesse caratteristiche di composizione e tipo di materiale, ma non hanno alcuna continuità fisica.

L'US 112 è stata individuata nell'area compresa fra l'Ambiente 4 e il muro 9 e ha restituito una grande quantità di ceramica (in particolare ceramica sigillata italica), oltre a monete e ceramica commune mentre l'US 118 si estendeva nell'area compresa fra l'USM 18 e il muro $8^{15}$.

Fra il materiale relativo all'US 118, si segnala una fibula in bronzo che sembra attribuibile al tipo Hod Hill, di cui si conoscono numerosi esemplari attestati in Svizzera, nel Berry, in Borgogna e nella Renania a partire dall'epoca di Claudio ${ }^{16}$. Quest'ultima manca di ardiglione e nella staffa presenta un foro. In attesa di una pulitura più approfondita dell'oggetto è ancora impossibile fornirne una descrizione più dettagliata (fig. 5).

\section{Fig. 5 - Castrum Novum. Fibula di I secolo d. C.}

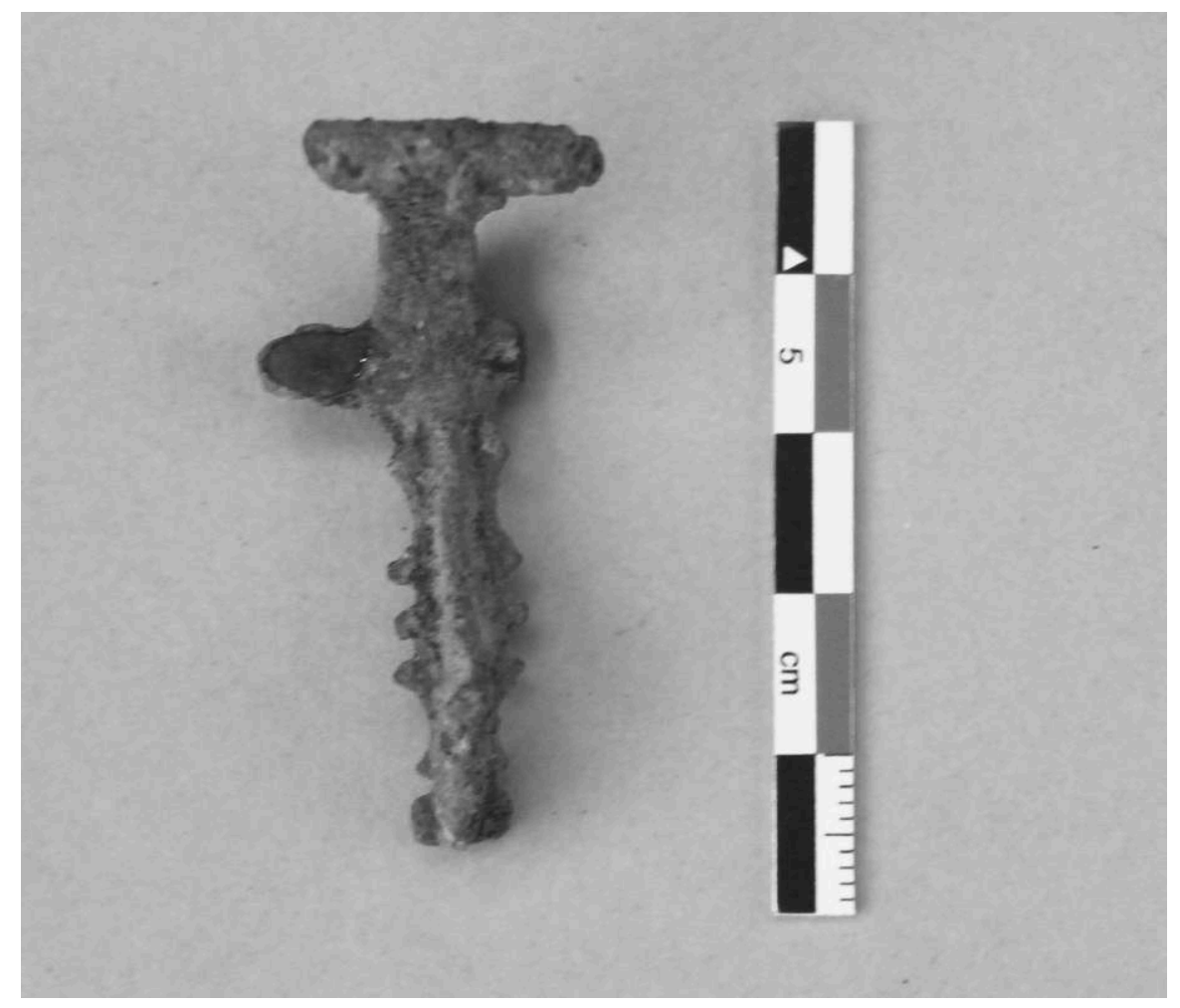

S. NARDI-COMBESCURE.

Le USM 17 e 18 costituiscono le spallette del prefurnio situato nel lato orientale del tepidarium Ambiente 3, che si appaggiano direttamente alle spallette della fogna (USM 20 e USM 21). Del prefurnio, oltre alle spallette si conservano dei filari di laterizi, relativi ad una volta, il cui crollo è stato rinvenuto all'interno del canale (US 117). L'insieme di questi elementi (comprese le USM 17 e 18) riposa su uno strato (US 122), caratterizzato da malta grigia con tracce di cenere e carbone che attestano l'uso della 
struttura. Quest'ultimo sembra perfettamente orientato con l'Ambiente 4, per la cui destinazione resta ancora si rimanda oltre al contributo di Alessandra Squaglia.

Le relazioni stratigrafiche fra l'US 122 e le strutture dell'Ambiente 4 dovranno essere verificate nel corso della prossima campagna di scavi 2014.

\section{Area prospiciente l'ambiente 5}

21 Nell'area prospicente la forica (Ambiente 5) e il prefurnio del caldarium (Ambiente 6), l'allargamento del sondaggio di scavo, in direzione ovest ha portato al rinvenimento di due nuovi muri (26 e 27) che sembrano delimitare un corridoio di accesso all'Ambiente 6.

All'interno dell'US 202, primo strato non inquinato da materiale moderno, è stata rinvenuta una fistula plumbea con iscrizione, lunga circa $50 \mathrm{~cm}$ e con un diametro di almeno 5 centimetri (fig. 6).

Fig. 6 - Castrum Novum. Fistula plumbea, US 202.

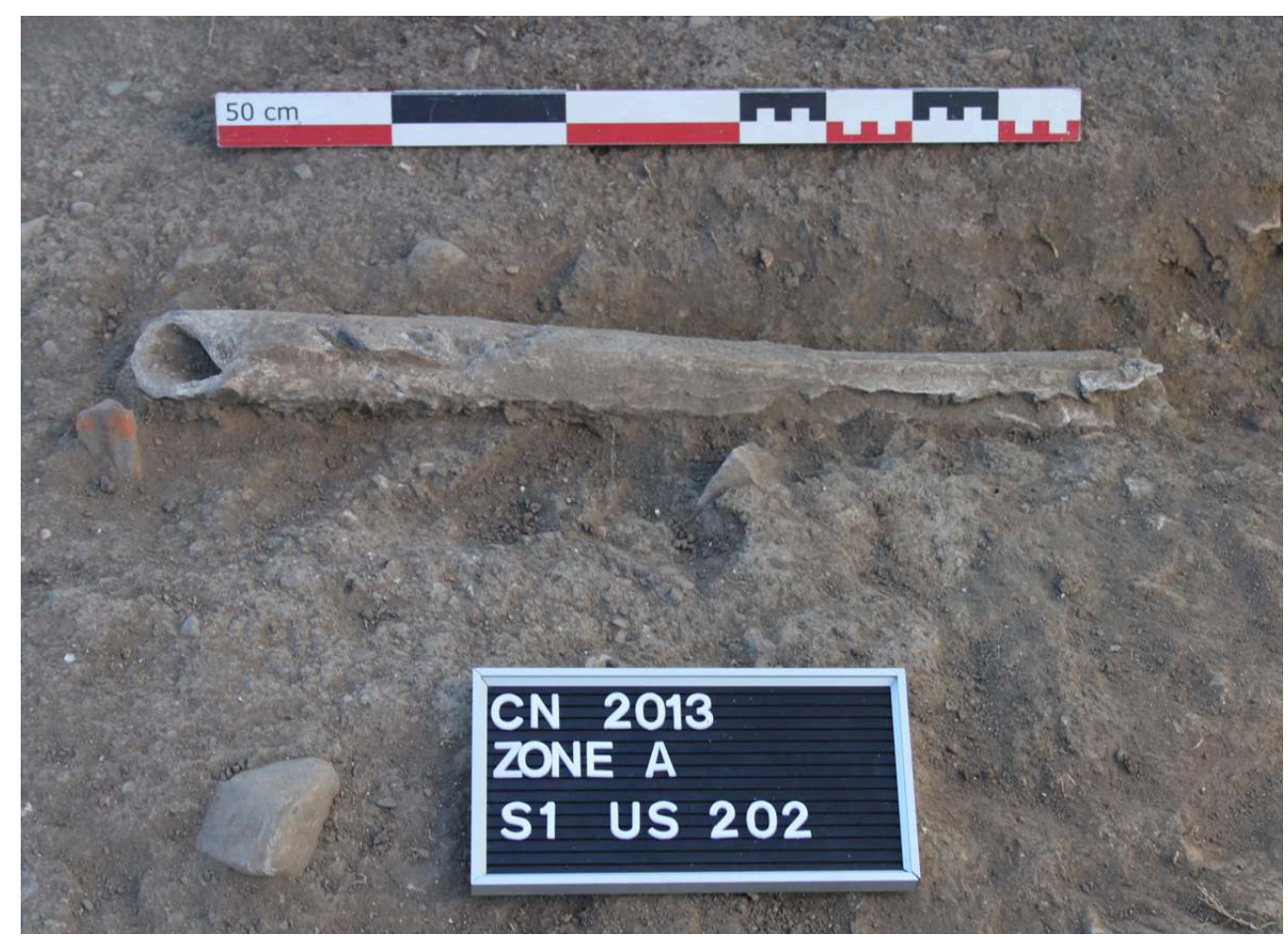

S. NARDI-COMBESCURE.

La fistula è stata segata in uno dei suoi lati, al fine di recuperare una parte del metallo ${ }^{17}$.

\section{Zona A, settore 1 : le balneum de « le Guardiole ». Les inscriptions découvertes lors de la campagne 2013 (Marie-Laurence Haack)}

24 La campagne 2013 a permis de découvrir dans la zone des thermes les six inscriptions suivantes. 


\section{Inscriptions sur des céramiques sigillées italiques}

1) Estampille in planta pedis sur fond interne de vase arétin découvert dans l'US 111. L'inscription est au centre d'un cercle et se lit de la façon suivante :

P(ublius) LORE(ius) CRET(icus)

L'inscription est connue par trois exemples, tous d'Italie centrale ${ }^{18}$. L'inscription remonte à une période qui va de 15 après $\mathrm{J}$.-C. à la fin du $1^{\mathrm{er}}$ siècle après $\mathrm{J}$.-C.

2) Inscription sur le fond externe d'un vase arétin trouvé dans les thermes (US 112).

Les lettres sont gravées après cuisson et disposées en arc de cercle.

T III HS

\section{Estampilles sur briques}

3) Estampille sur une brique bipédale de l'égout retrouvé dans les thermes (canal 1) (fig. 1).

CN(aei) DOMIT(i) APRILIS

La formule onomastique est connue par d'autres briques à estampilles de Rome (CIL, XV 1110, 7 ; CIL, XV 1110, 8), en particulier du Palatin (CIL, XV 1109; CIL, XV 1110, 1 ; CIL, XV 1110, 2 ; CIL, XV 1110, 3 ; CIL, XV 1110, 4 ; CIL, XV 1110, 5), et par une inscription de Chiaruccia à Santa Marinella (CIL, XV 1110, $6=$ CIL, XI 6672, 67). Ces inscriptions sont datables de 120 après J.-C.

4) Estampille sur une brique bipédale brisée du canal 1 (fig. 2).

L'estampille est amputée de la moitié de son texte. L'inscription se lit difficilement. Peut-être faut-il comprendre :

$$
\text { [- - - ]I APRI[- - ] }
$$

On hésite à compléter CN(aei) DOMIT(i) APRILIS comme dans l'inscription présentée audessus.

5) Estampille sur une brique bipédale des thermes (US 123) :

[opus doliare ex figlinis] CLA(udi) / ALEXANDRI

L'inscription est connue par plusieurs attestations: à S. Severa, dans les fouilles de l'église de la Piazza della Rocca (F. Enei (éd.), Santa Severa tra leggenda e realtà storica. Pyrgi e il castello di Santa Severa alla luce delle recenti scoperte (Scavi 2003-2009), Pyrgi-Santa Severa, 2013, n 2-4), à Alsium (CIL, XV 2165, 1 = CIL, XI 6689, 76), à Ostie (CIL, XV 2165, 2 $\mathrm{a}=C I L$, XIV 89, $28^{\circ}=$ IPOstie-B, 386, $15 \mathrm{a} ; C I L$, XV 2165, 2 b = CIL, XIV 4089, 28 b = IPOstie$\mathrm{B}, 386,15 \mathrm{~b})$ et à Rome (CIL, XV 7945).

Elle est datable du $2^{\mathrm{e}}$ siècle après J.-C.

Bibliographie : CIL, XV 1, 2165 ; M. Steinby, Lateres signati ostienses, Rome, 1978, nº 1147.

\section{Inscription sur fistule}

6) Inscription sur fistule de plomb trouvée dans la zone des thermes (US 202) (fig. 4).

[- - -]DI[---] L(V)NENSIS [- - - ]

L'inscription est très mutilée, puisque le timbre conservé fait environ $15 \mathrm{~cm}$, alors que les timbres ont une longueur habituelle de $29,6 \mathrm{~cm}$, ce qui signifie que le nombre de 
lettres manquantes est relativement important. Seul le cognomen Lunensis est lisible ; or, il n'est attesté sur aucune inscription éditée de fistule.

\section{Zona A, settore 1 : il balneum de « le Guardiole ». La ceramica (Luca Desibio)}

Come è noto il settore I, all'interno della zona $\mathrm{A}$, corrisponde ad un complesso termale di modeste dimensioni. La classe ceramica più antica qui rinvenuta, è rappresentata da diversi frammenti di vernice nera databile all'età romano-repubblicana (II-I sec. a. C.).

Notevole è la quantità di frammenti di ceramica comune, tra i quali è stato possibile identificare almeno un orlo di olla, inquadrabile tra la prima e la seconda metà del II sec. a. C. e un orlo di olla databile tra il 120 ed il 140 d. C., entrambi rinvenuti all'interno dell'ambiente 3 interpretato come un tepidarium ${ }^{20}$.

Dall'US 111, strato compreso tra gli Ambienti 4, 6 e 3, proviente un orlo di coppa riconducibile alla produzione tardo-italica, databile tra la prima metà del I sec. d. C. e gli inizi del II sec. d. C. ; sempre l'US 111 ha restituito inoltre una notevole quantità di frammenti di ceramica sigillata africana.

Anche in questo settore, la classe ceramica africana detta "a patina cenerognola » appare assai ben attestata da diversi frammenti.

L'area che ha restituito la più elevata quantità di materiale ceramico (ma non solo anche vitreo e metallico) è quella copresa nel sondaggio I, ubicato nell'area nord-est del complesso termale : quest'ultimo è stato scavato solo recentemenre e non fa parte di quella serie di ambienti già messi in luce durante le campagne di scavo effettuate dalla Soprintendenza archeologica per l'Etruria meridionale negli anni ' $70^{21}$.

9 A differenza del vicino edificio a pianta quadrata, la classe della ceramica sigillata appare poco attestata da un punto di vista quantitativo ma assai rilevante per la sua qualità : uno dei reperti meglio conservati è rappresentato da una parte di coppetta composta da due frammenti con decorazione esterna raffigurante una figura umana (fig. 7). 
Fig. 7 - Castrum Novum. Frammenti di coppa in sigillata tardo italica decorata.
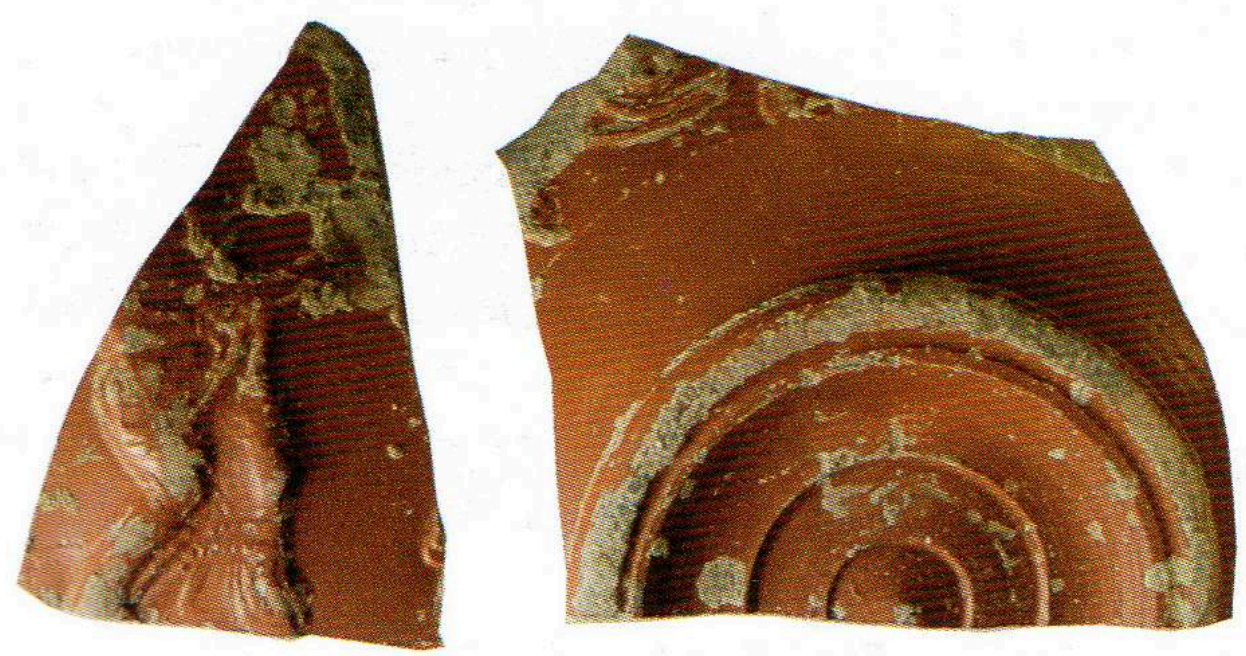

L. DESIBIO.

Al suo interno sono stati recuperati diversi frammenti di terracotta architettonica, vetri (circa 110 frammenti, tra i quali spicca un piccolo unguentario, tessere di mosaico e numerosi frammenti di anfore di diverse tipologie ed alcuni oggetti metallici (fig. 8), tra $\mathrm{i}$ quali la fibula in bronzo già descrittan nuomerosi frammenti di ceramica comune $\mathrm{e}$ ossa : si segnala inoltre il rinvenimento di un frammento di orlo appartenente ad un dolium, grande contenitore usato per la raccolta e lo stoccaggio degli alimenti e di un piccolo frammento di impasto non tornito.

Fig. 8 - Castrum Novum. Oggetti in metallo dal balneum de " Le Guardiole ».
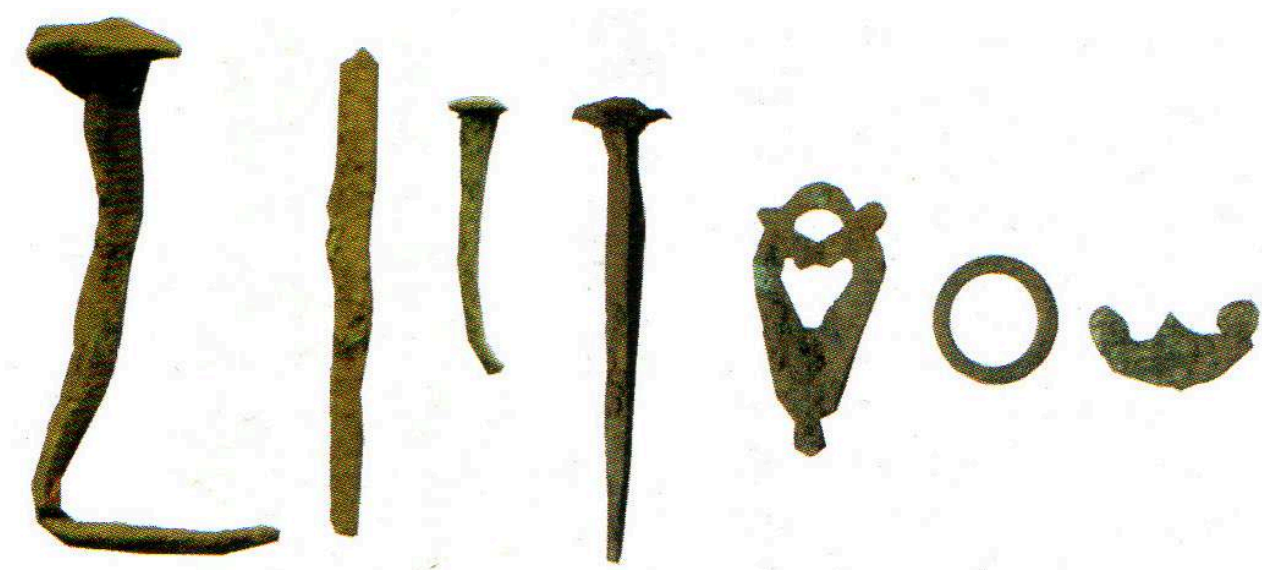

L. DESIBIO. 


\section{Zona A, settore 1 : il balneum de "le Guardiole". Analisi preliminari delle strutture murarie del balneum (Alessandra Squaglia)}

51 Queste brevi note sono volte ad illustrare le analisi preliminari sulle strutture murarie afferenti il cosiddetto balneum situato nella località "Le Guardiole », corrispondente all'antica Castrum Novum ${ }^{22}$.

52 Come abbiamo già visto, le campagne di scavo condotte dal 2010 al 2013 hanno riportato all'attenzione degli studiosi una serie di strutture di epoca romana, già indagate dalla Soprintendenza archeologica per l'Etruria meridionale nel 1970 e pubblicate in seguito da P. A. Gianfrotta ${ }^{23}$.

53 Per quanto concerne l'analisi del monumento, mi è sembrato utile proporre uno sguardo sinottico e comparativo tra i dati a nostra disposizione desumibili sia dallo studio precedente sia dalle recenti acquisizioni.

Le rovine del balneum risultano articolate in diversi ambienti orientati nord est-sud ovest. Un confronto tra le planimetrie dell'edificio termale, pubblicate rispettivamente nel 1972 e nel 2013 permette di chiarire quali settori dell'edificio sono stati rimessi in luce dalle ultime campagne di scavo ${ }^{24}$ (fig. 9).

Fig. 9 - Castrum Novum. Il balneum de "Le Guardiole », con indicati i diversi ambienti.

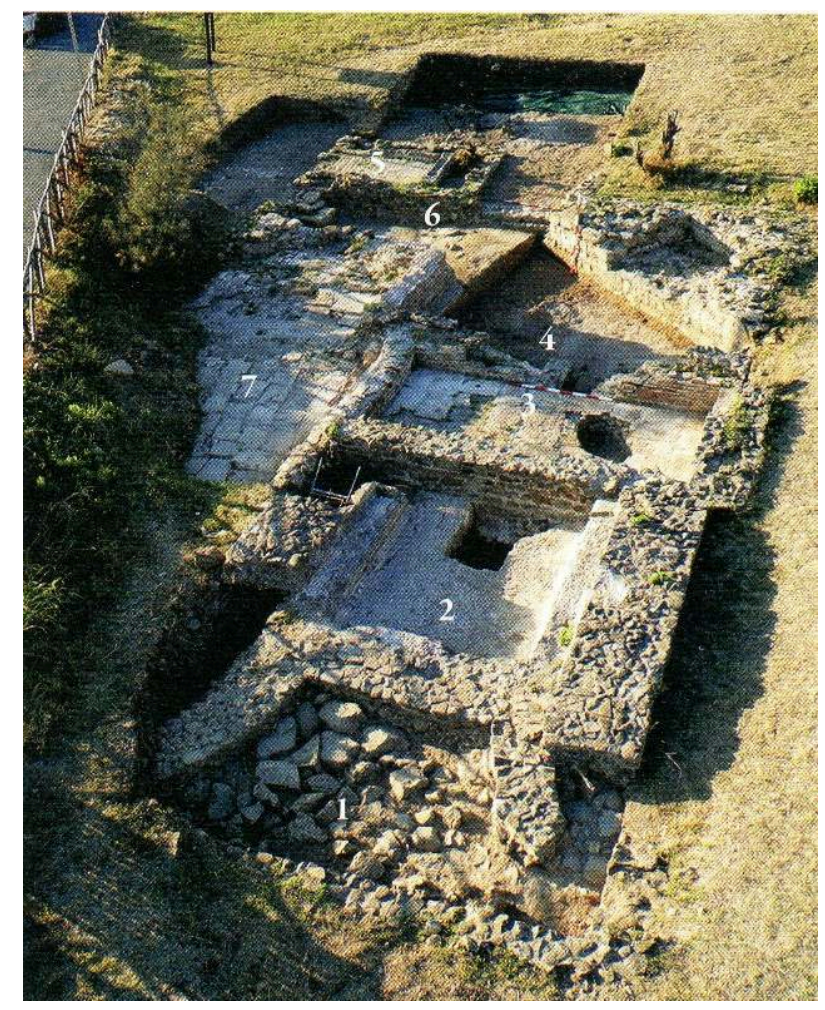

F. ENEI.

55 Le strutture esaminate sono state considerate dagli studi precedenti come parte di una villa marittima individuata lungo la riva del mare in corrispondenza di alcune peschiere ancora ben visibili ${ }^{25}$. 

accumulo successive allo scavo del 1970 e per questo motivo non riportato nella planimetria del 2013. Lo studioso descrive la presenza di tracce di pavimento a mosaico di tessere bianche e nere, poggiante su massetto di schegge di pietra e frammenti di laterizio legati con calce ${ }^{27}$. L'ambiente 1 del balneum (fig. 9), indagato per la prima volta nel settembre 2013, presenta un riempimento costituito da grosse pietre informi da collegare presumibilmente ad una seconda fase del balneum caratterizzata dal taglio della vasca del frigidarium e dall'ostruzione del condotto di alimentazione dell'acqua. La vasca in cocciopesto indicata come Ambiente 2 (fig. 10) nella pubblicazione del 1972 presentava nel fondo un'interruzione in corrispondenza del muro 5 interpretata in un primo tempo come una fossa di spoliazione clandestina.

Fig. 10 - Castrum Novum. Ambiente 2 con vasca in cocciopesto.

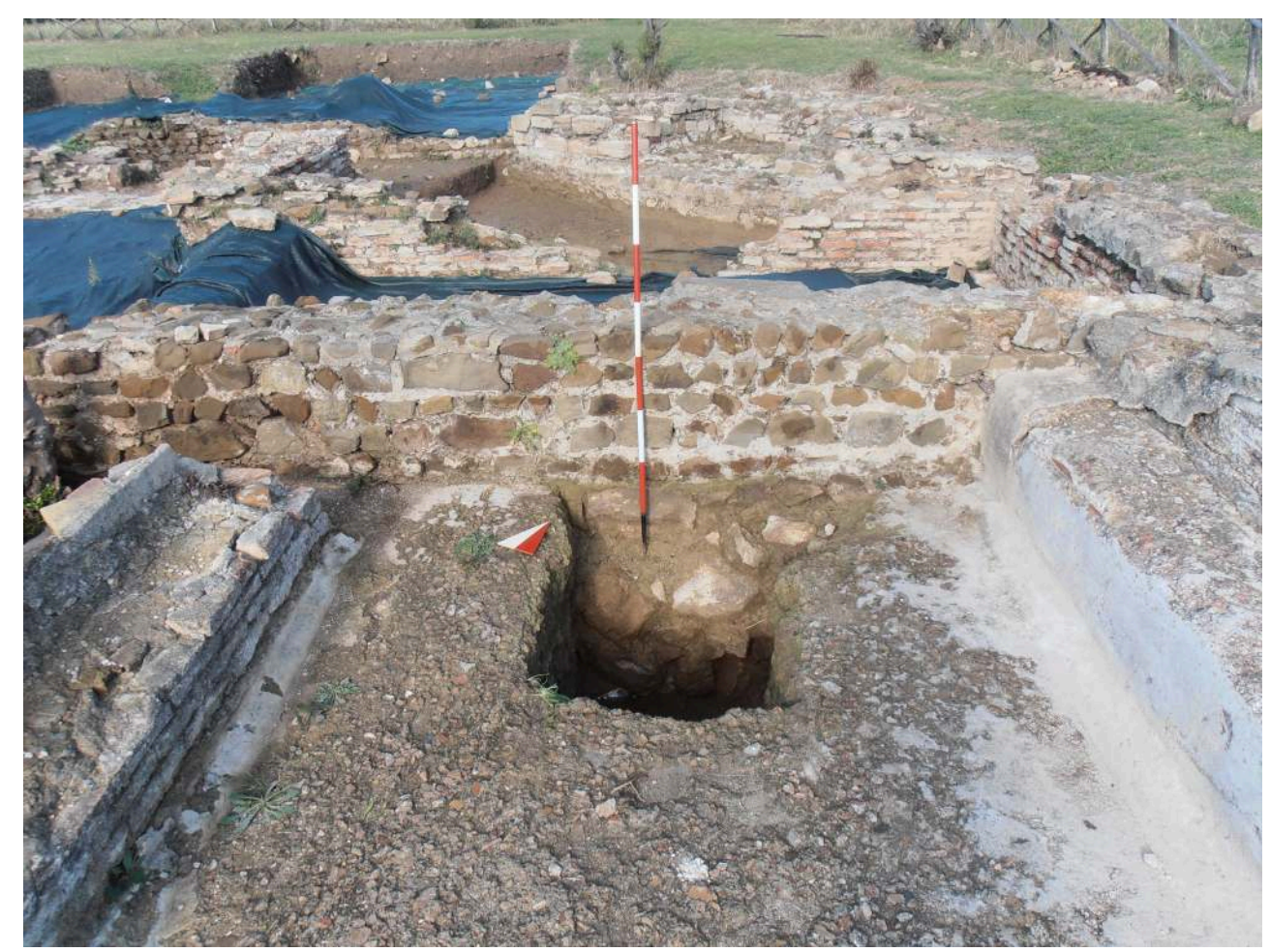

A. SQUAgLIA.

Le indagini condotte nel settembre 2013 hanno rivelato invece l'esistenza di un condotto idraulico obliterato da grossi massi di pietra locale (Canale 1) ${ }^{28}$. Il ritrovamento di un laterizio ancora in situ all'interno del condotto recante il bollo APRILIS CN (aei) DOMIT(i )datato al 120 d. C. ${ }^{29}$, costituisce senza ombra di dubbio un terminus post quem per la costruzione del canale idraulico e della vasca. Al momento dell'occlusione del condotto la vasca venne tagliata dalla costruzione del muro $5^{30}$, il quale tagliò anche uno scolo in calcestruzzo destinato al deflusso delle acque.

59 Adiacenti alla vasca due ambienti di diversa grandezza (A3, A7) conservavano nel 1970 alcune suspensurae in bessali, in origine alte circa m 0,50 e lungo le pareti tubuli in terracotta per il passaggio dell'aria calda ${ }^{31}$. Entrambi gli ambienti costituivano 
l'intercapedine dell'ipocausto. Le pareti interne degli ambienti A3 e A7 appaiono rivestite da mattoni e tegole in filari regolari. Altri due ambienti, a nord, in origine comunicanti tra loro e ad un livello leggermente inferiore rispetto agli ambienti con suspensurae erano forniti da due prefurnia, di cui quello dell'Ambiente 7 nel 1970 conservava ancora l'archetto in laterizio ${ }^{32}$.

Gli ambienti con suspensurae e praefurnia presentano coerenza costruttiva. L'ambiente A3 è delimitato dai muri 5, 6, 7, 8, 9. I paramenti dei muri 8 e 9 (USM 6), appaiono come un opus mixtum con pannelli inquadrati da blocchetti squadrati di pietre e tegole ${ }^{33}$ (fig. 11).

Fig. 11 - Castrum Novum. Paramenti dei muri 8 e 9.

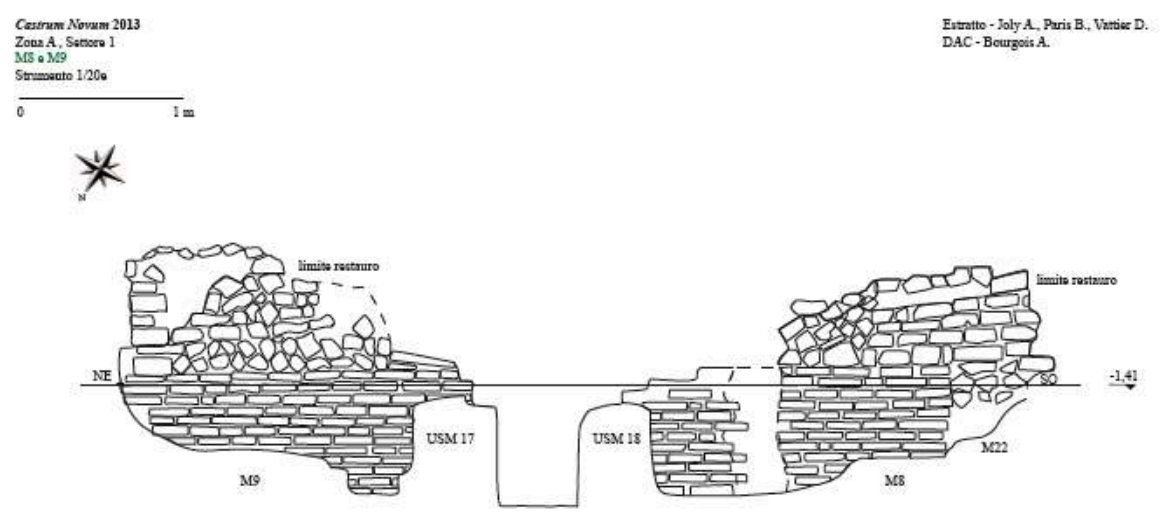

\section{A. JOLY, B. PARIS, D. VATTIER, A. BOURgEOIS.}

Il secondo ambiente con ipocausto (A7) presenta le pareti rivestite da un muro di tegole e mattoni disposti in filari regolari; ambedue gli ambienti hanno restituito un pavimento composto da uno strato di tegole rettangolari legate da malta grigio chiara ${ }^{34}$. Questi due ambienti presumibilmente da assimilare ad un tepidarium (A3 ?) e un caldarium (A7 ?) dovevano essere collegati ad un frigidarium identificabile con la vasca in coccio pesto già analizzata. La logica considerazione dalla quale scaturisce l'identificazione dei tre ambienti della villa con quelli destinati ad un uso termale si scontra però con l'interruzione della vasca da parte del muro 5 dell'ambiente con suspensurae A3. L'interruzione dell'uso della vasca, in base ai dati archeologici finora a nostra disposizione, sembrerebbe collocarsi non oltre la fine del III secolo d. C., epoca in cui verrebbero edificati A3 e A7.

Ammettendo l'esistenza di due fasi costruttive del supposto edificio termale ${ }^{35}$ fasi risalenti rispettivamente al I-II secolo e al III secolo d. C., resta da chiarire il perché del taglio della vasca del supposto frigidarium, l'obliterazione del condotto e di parte della struttura meridionale mediante il già citato riempimento di grossi blocchi. Si potrebbe ipotizzare la ricostruzione di una nuova vasca in un altro settore dell'edificio e 
precisamente nella parte non indagabile sotto la Via Aurelia subito ad est dell'ambiente con suspensurae $\mathrm{A}^{36}$.

A nord dei suddetti ambienti una forica (A5) fu riportata alla luce già nel $1970^{37}$. L'ambiente è ancora in buono stato di conservazione. I muri perimetrali sono in pezzame di pietra calcarea locale, il pavimento in opus spicatum inquadrato da un canaletto rivestito di cocciopesto.

Stando ai dati relativi allo scavo del 1970, l'intera area era ricoperta da uno strato archeologico risalente ai primi decenni del II secolo e non si rinvennero «neppure sporadicamente, materiali posteriori a tale epoca $»^{38}$. Tale affermazione, considerata suscettibile di variazioni già dallo stesso Gianfrotta che l'aveva formulata ${ }^{39}$ oggi può essere rivista alla luce degli studi preliminari effettuati sui materiali rinvenuti durante le campagne di scavo 2010-2013 e che documentano una frequentazione dell'area termale dall'epoca augustea fino al III secolo d. C..$^{40}$.

Gli scavi del 1970 riportarono alla luce i resti di un ambiente (A4) che però non venne analizzato da Gianfrotta ma fu rilevato nella planimetria generale dello scavo redatta all'epoca (fig. 12).

Fig. 12 - Castrum Novum. L'Ambiente 4.

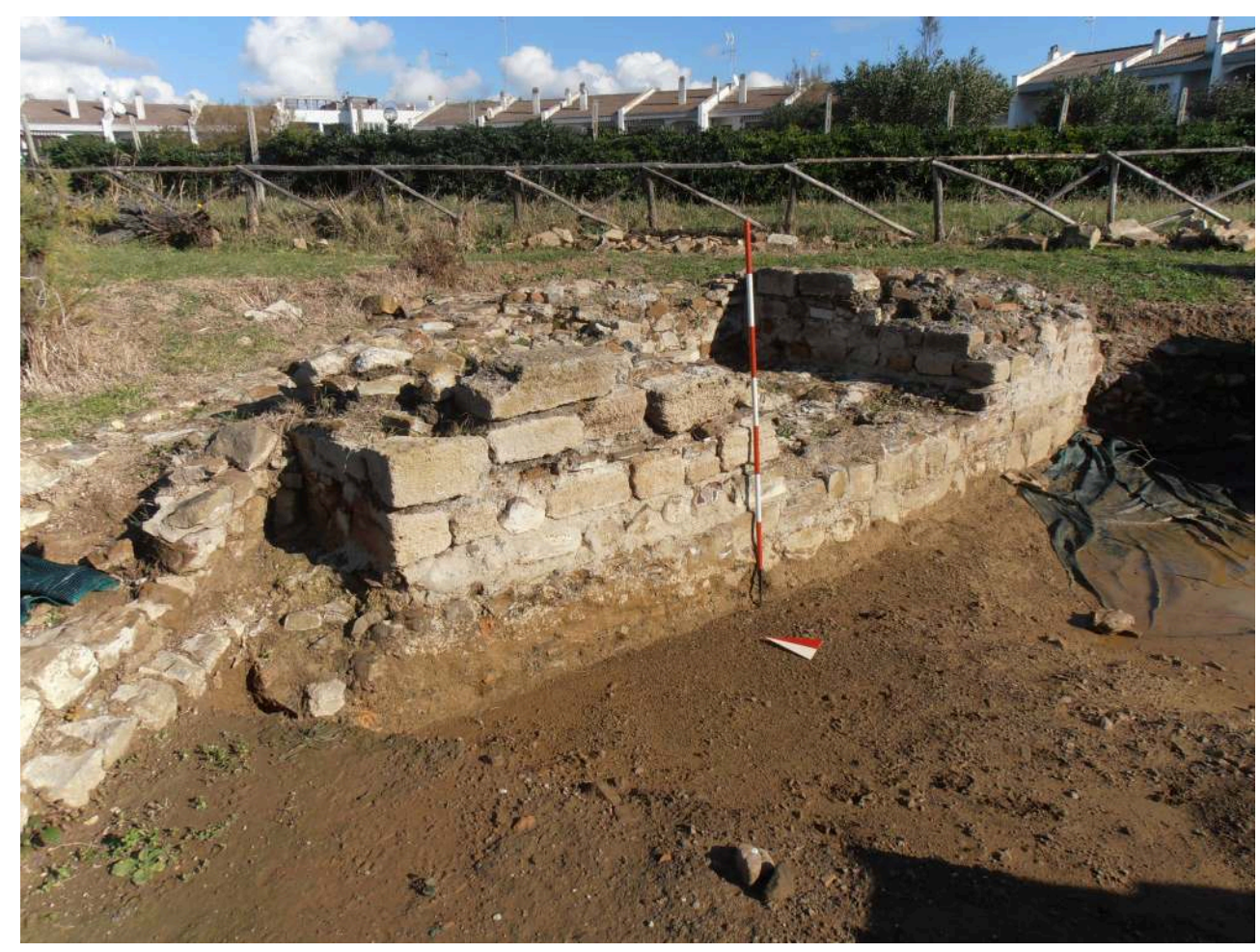

A. SQUAgLIA.

L'ambiente è ricavato in un angolo del balneum in modo tale da assumere una forma triangolare. Si tratta di una struttura in opera cementizia, orientata nord-sud con apertura a sud, il cui paramento è costituito da blocchi di scaglia, pezzame di calcare locale e tegole di reimpiego disposte su filari regolari. E' presumibile che l'ambiente, la cui funzione è ancora da stabilire con certezza, risalga ad una fase tarda dell'edificio termale coincidente forse con il suo abbandono ${ }^{41}$. I materiali di recupero provenienti dal balneum potrebbero far risalire la sua costruzione in un'epoca in cui l'impianto era 
ancora visibile ma non più utilizzato ${ }^{42}$. La struttura orientata verso l'antico diverticolo della Via Aurelia potrebbe essere pertinente ad una fortificazione, forse una torretta da collocare cronologicamente tra il V-VI e l'VIII secolo ${ }^{43}$, periodo storico che vide la decadenza di Castrum Novum come centro costiero in concomitanza con le guerre grecogotiche e le invasioni barbariche ${ }^{44}$. Alla presenza di una postazione di difesa o avvistamento sul territorio potrebbe essere infine collegato lo stesso toponimo «Le Guardiole » dell'area presa in esame. Esso infatti potrebbe derivare dal termine longobardo warda che significa « luogo di osservazione, postazione di guardia $»^{45}$.

\section{Zona $\mathrm{A}$, settore 2 : l'edificio quadrato sull'antica via Aurelia (Flavio Enei)}

Le nuove indagini hanno permesso di approfondire la conoscenza del complesso a pianta quadrangolare, a suo tempo definito villa, aperto direttamente sulla via glareata che si è voluto identificare con la sede della via Aurelia Vetus ${ }^{46}$. La ripulitura delle strutture messe in luce in occasione degli scavi del 1972 e l'esplorazione di alcuni settori all'epoca non indagati, ha consentito di acquisire una nuova planimetria dell'edificio e di raccogliere ulteriori informazioni, relative alla sua frequentazione e alle diverse fasi edilizie (fig. 13) ${ }^{47}$.

Fig. 13 - Castrum Novum. Pianta dell'edificio quadrato.

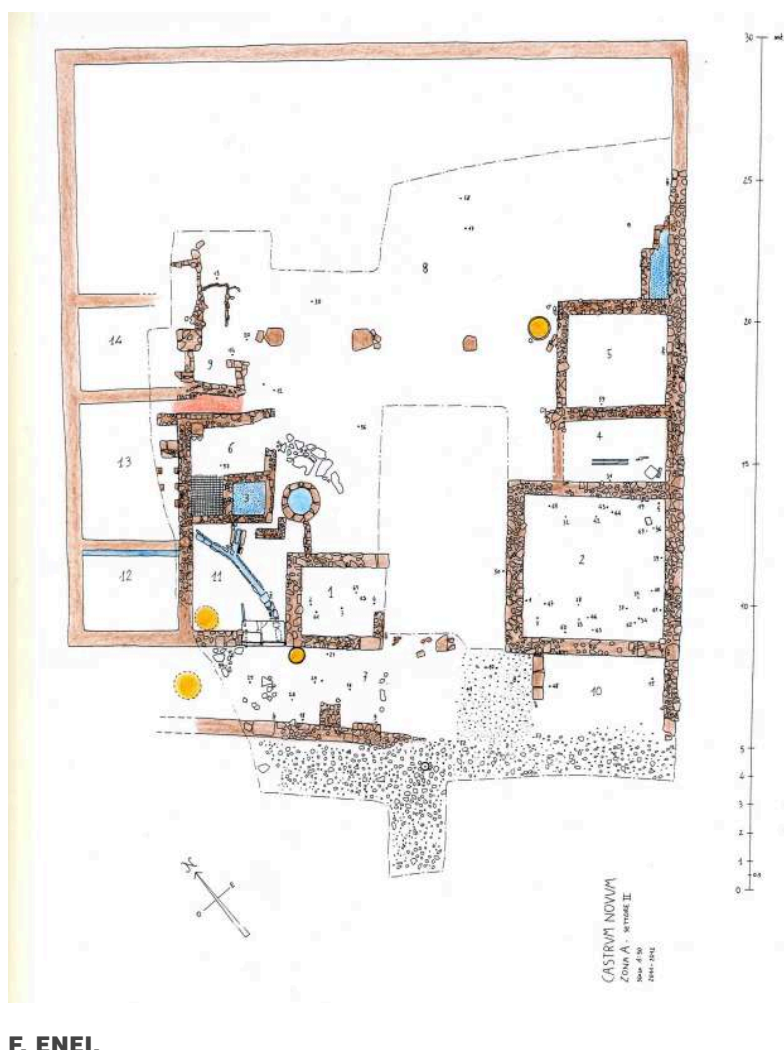

L'edificio si presenta a pianta quadrata con lati di circa 22 metri, orientato nordest / sud-ovest con accesso dalla strada, rivolto in direzione del mare verso sud-ovest. 
L'intera costruzione risulta edificata in pietra locale con muri formati da scapoli di calcare, macigno, scaglia, pietraforte e qualche ciottolo fluitato uniti con argilla e poca malta ricca di calce. Una tecnica edilizia semplice con uso parsimonioso di laterizi limitato ad alcune specifiche strutture.

Evidente all'interno delle murature il riuso di blocchi squadrati in scaglia, di certo pertinenti ad una fase edilizia più antica dell'edificio stesso o di un altro sito nelle vicinanze.

71 Nel suo interno la costruzione si articola in almeno 14 ambienti diversi per alcuni dei quali è stato possibile riconoscere le originarie funzioni.

I dati disponibili consentono di ricostruire l'esistenza di un probabile portico, ampio circa 3 metri, situato sulla fronte dell'edificio a protezione dell'ingresso (Ambiente 7).

73 Di tale struttura restano le fondazioni del muro rivolto alla strada e quelle di due pilastri che dovevano sorreggere il tetto. Lo scavo ha evidenziato i resti dell'ultimo piano di calpestio, caratterizzato da un fitto battuto di frammenti di scaglia nella zona sud, di ciottoli e frammenti di tegole nella parte nord dove, durante gli scavi del 1972, venne documentata la presenza dei resti di un dolio oggi non più rilevabili ${ }^{48}$. Le numerose monete rinvenute sul piano di calpestio e i resti di un macinello manuale in pietra lavica trovato sulla strada segnalano in loco la presenza di probabili attività commerciali (fig. 14).

Fig. 14 - Castrum Novum. II macinello in pietra lavica.

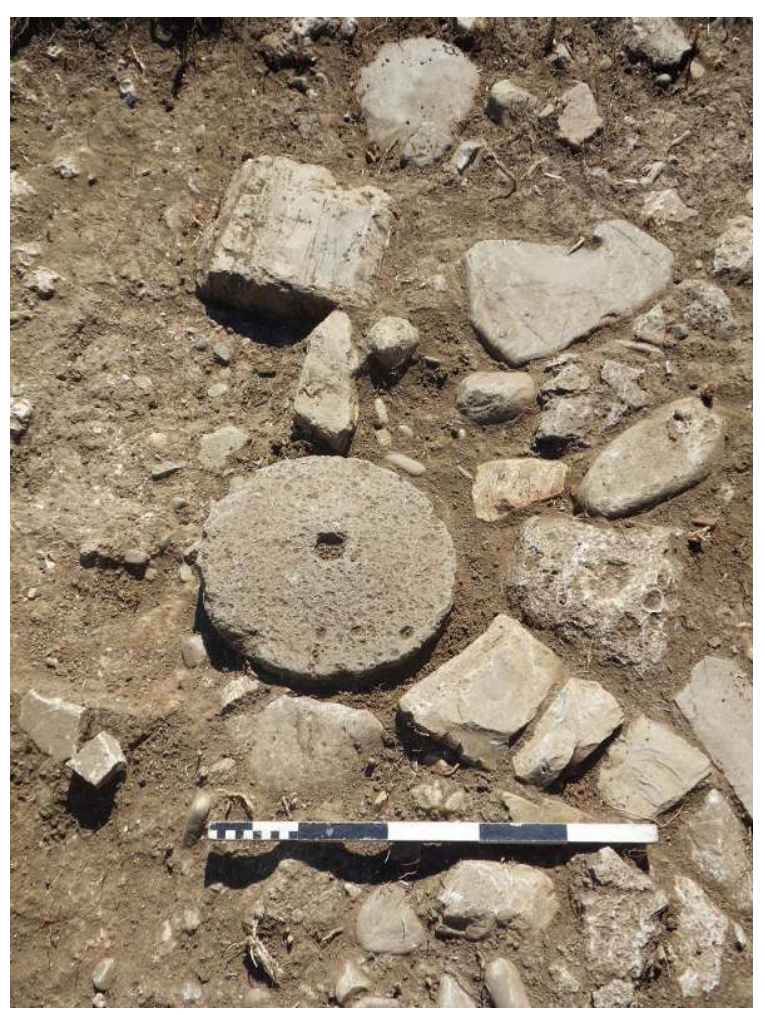

F. ENEI.

74 Il lato meridionale del portico sembrerebbe chiuso da un ambiente rettangolare, appoggiato alle murature preesistenti, con un lato interamente costruito in blocchi squadrati di scaglia di chiaro riutilizzo (Ambiente 10). Il ritrovamento al suo interno di 
un ago da rete e di un amo in bronzo, dei gusci di alcuni molluschi bivalvi e di un peso da bilancia potrebbe far identificare il piccolo ambiente come possibile sede di una taberna gestita da pescatori, sita fronte strada, per la rivendita di pesce e molluschi.

L'ingresso principale dell'edificio doveva aprirsi quasi nel mezzo del lato sud della costruzione in un tratto di muro oggi quasi scomparso a causa di antiche e moderne asportazioni di materiale. Un secondo ingresso, sempre protetto dal portico, è invece ancora ben riconoscibile pochi metri più a nord. In questo caso si conserva la soglia della porta in lastre di scaglia, ampia circa $1,50 \mathrm{~m}$, con ancora evidenti le tracce dell'alloggio dei cardini e la parte inferiore di un originario stipite laterale realizzato con lo stesso materiale. Lo scavo dell'area circostante ha messo in luce i resti di un'anfora, una probabile Dressel 20, tagliata a metà ed infissa nel terreno subito sul lato destro dell'ingresso come probabile vaschetta di raccolta. Di notevole interesse i dati provenienti dallo scavo dello strato di preparazione per l'alloggiamento della soglia, contenente alcuni frammenti di ceramica africana da cucina, databili nel I-II secolo d. C. che costituiscono un interessante terminus post quem per la messa in opera dell'elemento architettonico. Lo strato di preparazione copriva anche i resti di una conduttura in piombo (fistula aquaria) ancora collocata nella sua posizione originale, tagliata in due frammenti, passante subito al di sotto della porta. L'interno dell'edificio si rivela caratterizzato da uno schema regolare con ambienti distribuiti sui rispettivi lati di una

zona centrale ancora non indagata, probabile atrio-cortile, e con un ampio porticato che chiude il lato opposto all'ingresso, appoggiandosi al muro di fondo della costruzione.

Entrando sulla destra il lato meridionale è occupato da tre ambienti affiancati, di diverse dimensioni e probabili funzioni (Ambienti 2, 4, 5).

L'Ambiente 2 si rivela una grande stanza a pianta quadrata, di $5 \mathrm{~m}$. di lato, con murature spesse circa $60 \mathrm{~cm}$. Lo scavo tuttora in corso non ha ancora raggiunto livelli pavimentali ma nello strato di abbandono sono presenti interessanti reperti che potrebbero essere utili per l'identificazione della sua funzione e delle attività svolte nel suo interno nell'ultima fase di vita. Di particolare interesse appare il ritrovamento di un grande peso da bilancia in marmo, un grosso uncino, chiodi e parte di una staffa triangolare con sommità ad anello, un filtro in piombo, monete e gusci di molluschi marini. Insieme a questo genere di oggetti, riconducibili ad attività di lavorazione di prodotti e possibile vendita, sono stati rinvenuti un balsamario in ceramica e un particolare piccolo oggetto in bronzo, caratterizzato da una lamina a forma di cuore sostenuta da un corto manico tornito, ricollegabili forse al maquillage femminile. Molto interessanti i risultati dello scavo condotto nel vicino Ambiente 4 (fig. 15) dove è stato possibile raggiungere il piano pavimentale formato da un battuto di terra, ciottoli fluitati e calce. 
Fig. 15 - Ambiente 4. Veduta generale.

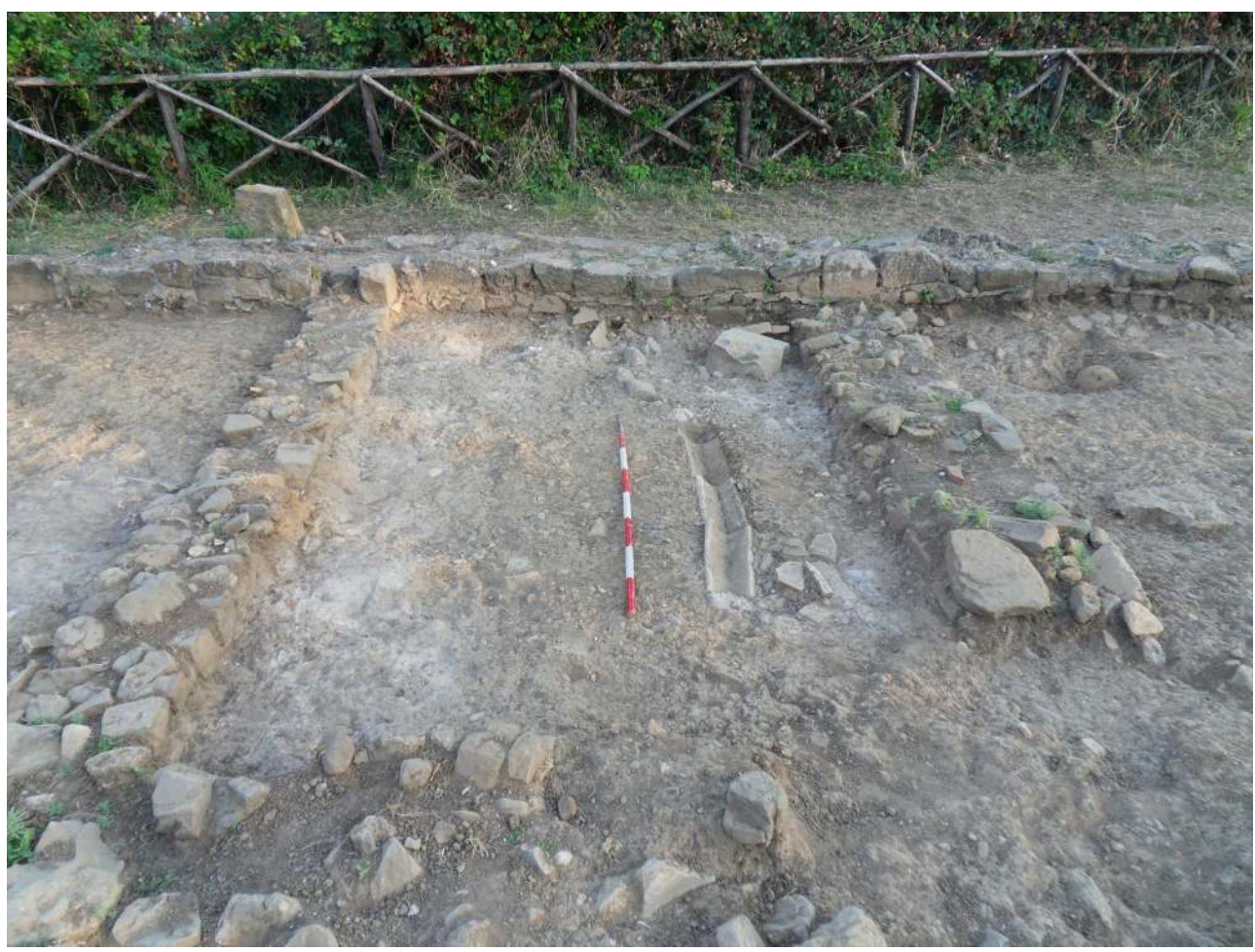

F. ENEI.

79 Nel pavimento è inserito un canaletto di scolo costruito con coppi rovesciati messi in opera con poca calce e argilla. Tale canale doveva essere posto ai piedi di un probabile banco da cucina del quale restano solo labili tracce dei pilastri laterali di sostegno, in pietra e tegole legate con malta ricca di calce, lungo il lato sud della stanza. Nello strato di abbandono che copriva il pavimento (US 18), sono stati rinvenuti numerosi frammenti di vasellame da cucina e da mensa che attestano la presenza di almeno 4 olle da fuoco, 3 coperchi, 2 tegami, 3 brocche, 2 anfore (Tipo Dressel 1) che insieme ai resti di gusci di molluschi e carboni consentono di identificare l'ambiente con una cucina provvista, inoltre di almeno una piccola lucerna con becco ad incudine, una coppa in vetro, un bicchiere a pareti sottili, un piatto in sigillata italica liscia e un balsamario in ceramica. Lo studio preliminare dei materiali sembra inquadrare il contesto e la datazione dei reperti più recenti nell'ambito dell'epoca augustea o giulio-claudia.

Ancora poche notizie ha fornito lo scavo appena iniziato dell'Ambiente 5 dove è tornata in luce una probabile soglia di porta, formata da più lastre in pietra, con uno scalino di

81 ingresso alla stanza a pianta quadrangolare di $m 3,50$ x 3,30. All'esterno dell'ambiente, a ridosso del muro, è affiorato il fondo di un dolio ancora in posto, presso l'angolo nord. Il dolium doveva essere collocato in piedi con la base interrata di circa $30 \mathrm{~cm}$ al di sotto dell'antico piano di calpestio.

Sul lato opposto all'area centrale scoperta, entrando nell'edificio, si trova una piccola stanza a pianta quasi quadrata, di $\mathrm{m} 2,50 \times 2,40$, con probabile porta d'ingresso sul lato rivolto a sud-est (Ambiente 1). Lo scavo ha messo in luce i resti dell'ultima pavimentazione realizzata in terra battuta con ciottoli fluitati, frammenti di tegole e poca calce, simile a quella rinvenuta nell'Ambiente 4. Nel piano di calpestio dell'ambiente si rintracciano i resti di un buco di palo con due frammenti di tegole 
usate come zeppe di riempimento, da interpretare come traccia relativa all'esistenza di una struttura lignea. Sul pavimento giacevano diverse monete due delle quali, un denario di Adriano del 134-138 d. C. e un dupondio di Commodo del 183 d. C., sembrano attestare la frequentazione della stanza nel pieno II secolo d. C. e probabilmente ancora nei primi decenni del seguente. Quasi adiacente al lato nord-est dell'Ambiente 1 è situato un pozzo per l'acqua, con imbocco a pianta circolare di circa $80 \mathrm{~cm}$, già individuato in occasione degli scavi degli anni Settanta e mai completamente esplorato, a causa dell'acqua ancora presente al suo interno ${ }^{49}$. Intorno alla struttura rimangono i resti di una pavimentazione a lastre di pietra irregolari con una sorta di condotto formato da un coppo disposto in verticale, inserito sul margine appositamente scavato di una lastra e riempito da uno strato di terra con all'interno frammenti di un'anfora di tipo Dressel 2/4. Potrebbe anche trattarsi anche in questo caso di un buco di palo con $\mathrm{i}$ relativi materiali d'inzeppatura e riempimento.

L'intero lato nord-ovest dell'edificio, alle spalle dell'Ambiente 1 e del pozzo, è caratterizzato dalla presenza di un piccolo complesso termale, un balneum comprendente una vasca fredda ed almeno un ambiente riscaldato. Ben leggibile nella sua pianta rettangolare di $3,20 \times 2,50 \mathrm{~m}$, risulta essere l'Ambiente 6 all'interno del quale, presso l'angolo meridionale, è situata una vasca quadrata di circa $1,10 \mathrm{~m}$ di lato con fondo e pareti rivestite in opus signinum (fig. 16).

\section{Fig. 16 - Castrum Novum. Ambiente 6. Veduta generale.}

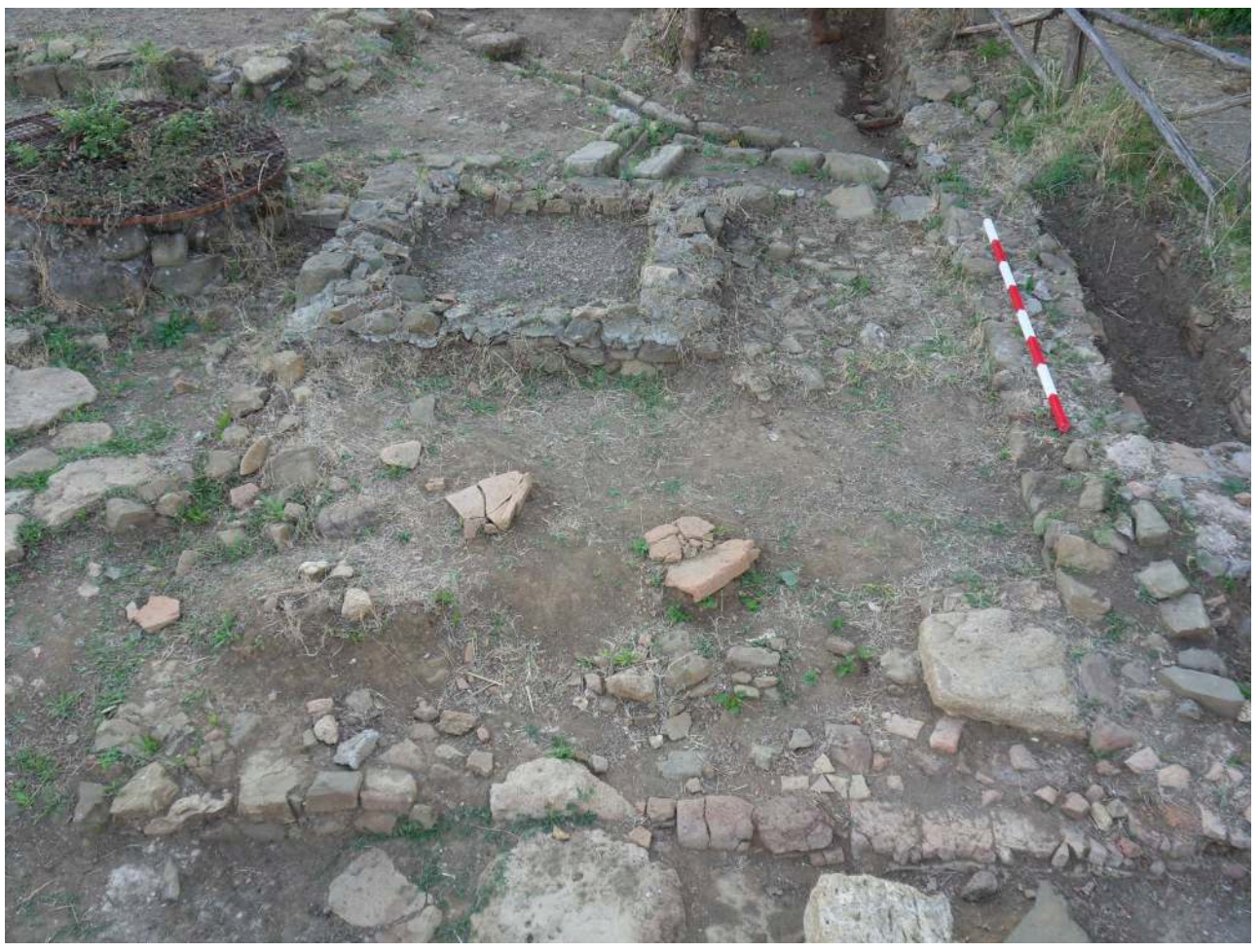

F. ENEI.

La stanza, probabile frigidarium, al momento dello scavo presentava i resti di un pavimento in cubetti di laterizio di circa $10 \mathrm{~cm}$, oggi scomparso ${ }^{50}$. Adiacente sul lato nord si trova un altro ambiente (Ambiente 13), a pianta rettangolare di m 5,00 x 3,50 circa, esplorato in occasione delle indagini degli anni Settanta e ora ricoperto al di sotto di una stradina vicinale in terra battuta. La struttura conservava in posto numerose 
pilae pertinenti all'intercapedine dell'impianto di riscaldamento, appoggiate su un fondo in sesquipedali. Tra le suspensurae risultavano crollati diversi grandi frammenti della pavimentazione musiva sovrastante, in origine stesa su un piano di mattoni bipedali.

Il mosaico, datato in epoca augustea, presentava il fondo formato da tessere bianche, messe in opera orizzontalmente disposte a formare un intreccio a canestro da cui ad intervalli regolari sporgono leggermente delle crocette di tessere nere con una bianca centrale, inserite in senso verticale, che danno luogo a filari rettilinei ${ }^{51}$. La presenza di una fistula plumbea per l'adduzione dell'acqua inserita nella parete nord dell'ambiente e il pavimento su suspensurae lascia ipotizzare l'esistenza di una vasca per immersioni in acqua calda all'interno di quello che sembra essere un caldarium. Il riscaldamento avveniva tramite un forno rinvenuto adiacente al muro nord dell'Ambiente 6. L'aria calda veniva immessa sotto al pavimento tramite un canale, lungo circa 2 metri e largo $60 \mathrm{~cm}$, con pareti rivestite in laterizi che si rivelano ipercotti e fortemente rovinati dall'esposizione al calore. La storia dell'Ambiente 13 termina con il crollo della pavimentazione musiva nell'intercapedine sottostante; nello strato di abbandono risulta scavata una fossa per ospitare una sepoltura infantile datata tra III e IV secolo ${ }^{52}$. Nell'area interessata dal balneum è compreso anche un altro ambiente di difficile identificazione, accessibile tramite l'ingresso laterale nel portico, ancora segnalato dalla soglia in posto. Si tratta dell'Ambiente 11 al di sotto del quale sono stati rintracciati due canali di scolo delle acque provenienti dalle vasche dell'impianto termale. Un breve tratto di fognatura, realizzata con coppi rovesciati protetti sui lati da lastre di scaglia, sembra fuoriuscire dalla vasca quadrata dell'Ambiente 6 per andare a confluire in una canaletta più lunga, foderata e coperta in lastre di pietra che, con una leggera pendenza, va ad infilarsi al di sotto della soglia d'ingresso, per proseguire in direzione della strada e del mare. Il canale principale di scolo è probabile che provenga dall'interno dell'Ambiente 13 dove doveva essere posizionata almeno una vasca calda. Tali impianti di spurgo delle acque dovevano passare al di sotto del livello pavimentale dell'Ambiente 11 del quale non sembrano restare tracce. E' probabile che fosse in terra battuta e ciottoli come gli altri rinvenuti nell'edificio. La stanza potrebbe essere identificata come un vano di ingresso verso i locali termali o viceversa in direzione dell'area centrale dell'edificio, passando vicino al pozzo, prima che un tramezzo in muratura lo chiudesse, nell'ultima fase di vita del complesso. Qualora l'ambiente non sia collegato agli altri vicini, potrebbe essere significativa la presenza di un dolio, situato nell'angolo nord-ovest della stanza, visto durante gli scavi del 1972 ma oggi non più rintracciabile, in quanto interrato sotto la strada vicinale. Il grande recipiente, addossato in piedi all'angolo tra due pareti, potrebbe indicare anche in questo caso una possibile destinazione commerciale della struttura, aperta sul portico prospiciente la strada.

Per concludere la descrizione dell'edificio nel suo insieme, va registrato che l'intero lato nord-ovest della costruzione risulta occupato da un ampia zona porticata, una tettoia che

doveva essere appoggiata al muro di recinzione di fondo e su almeno 4 grandi pilastri frontali (forse 5) le cui fondazioni sono state scoperte durante l'ultima campagna di scavi nel 2013. Sembra si tratti di pilastri in muratura, a pianta quadrata di almeno $60 \mathrm{~cm}$ di spessore, considerando che le strutture di fondazione si presentano con circa $80 \mathrm{~cm}$ di lato. 

compresa in un ampio settore dell'edificio finito al di sotto dei giardini delle villette adiacenti l'area archeologica. Nella zona indagata, nell'angolo nord-est, sono emersi i resti di una vaschetta rettangolare per l'acqua, addossata al muro e rivestita in cocciopesto, una probabile vasca di raccolta di una fontanella la cui funzione resta non interpretabile allo stato attuale delle conoscenze. Sullintera area circostante, coperto dallo strato di humus, è tornato in luce un notevole strato di macerie (US 5), composto quasi esclusivamente da scapoli di pietra insieme a numerose tegole e coppi da attribuire al crollo delle murature e del tetto dell'ambiente. La distribuzione e la posizione dei reperti, che appaiono non esattamente in situ, lasciano intravedere un possibile successivo livellamento del crollo avvenuto per fini di riuso dell'area e/o di spoglio del materiale. Dallo strato provengono un frammento di anfora del tipo Dressel 1 e due monete, una dell'imperatore Tiberio del 36-37 d. C. e una di Nerone risalente al 66 d. C. Sul lato opposto del porticato, verso l'angolo nord dell'edificio, lo scavo ha invece messo in luce le tracce di alcune strutture precarie di difficile identificazione, appoggiate al primo pilastro del portico, forse nelle ultime fasi di vita del complesso. Si tratta di brevi tratti di murature a secco che definiscono un piccolo ambiente (Ambiente 9) e almeno un altro recinto rettangolare di soli 1,40 x 0,80 m, formato con frammenti di tegole e lastrine di pietra infisse verticalmente nel terreno. All'interno del perimetro sussistono tracce di un battuto pavimentale in terra e piccoli ciottoli fluitati, tra i quali sono presenti alcuni manufatti attribuibili ad industrie preistoriche.

Allo stato attuale delle indagini il cosiddetto Edificio quadrato, a suo tempo identificato come una villa, sembra presentare delle caratteristiche anomale rispetto alla norma delle ville rurali note nel territorio e nell'Etruria tirrenica. Va rilevato che nel complesso non sono ancora stati individuati locali o resti di impianti certamente funzionali ad attività collegabili alla lavorazione di prodotti agricoli, come ad esempio un torcularium e una cella doliaria per la produzione vinicola o grandi macine da frantoio per la produzione di olio o di farina. Tali assenze lasciano immaginare che all'interno del complesso fossero ospitate funzioni ed attività diverse rispetto a quelle normalmente presenti nelle ville rustiche. Un importante settore dell'edificio, nell'angolo nord-ovest, è occupato da un piccolo balneum privato provvisto di almeno una vasca calda e di una fredda, molto spartano nella decorazione, privo di importanti rivestimenti marmorei. Tuttavia, qualora l'ingresso avvenisse anche dall'Ambiente 11, aperto verso la strada, si potrebbe anche pensare ad un uso della struttura non esclusivamente privato. I materiali rinvenuti nel portico e negli Ambienti 2 e 10 potrebbero indicare la presenza di attività commerciali legate forse alla rivendita del pescato. L'ampio spazio coperto, sito lungo il muro di fondo dell'edificio, potrebbe aver ospitato depositi, stalle per il bestiame e attività di lavorazione di vario genere. Interessante la presenza di una cucina provvista di un instrumentum formato, nel I secolo d. C., da una base di almeno 4 olle da fuoco e due tegami.

La posizione del complesso, aperto sulla strada, e la sua pianta simile a quella di una grande domus ad atrio di tipo pompeiano, potrebbero indicare una destinazione diversa da quella di centro di produzione agricola. Vale la pena considerare la possibilità che almeno nella fase di vita di epoca imperiale, nel I e II secolo d. C., l'edificio possa essere stato trasformato in una caupona, un'osteria con annessa rivendita di prodotti ittici e piccolo albergo con balneum per la sosta e il temporaneo ricovero di viandanti, in transito da e per Centumcellae. Restano da definire le fasi più antiche dell'edificio di

Chronique des activités archéologiques de l'École française de Rome , Italie centrale 
epoca romana repubblicana, indiziate dalla presenza di materiali edilizi riusati nelle murature, tra i quali diversi blocchi squadrati di scaglia, ceramiche a vernice nera e varie monete databili nel III-II secolo a. C., rinvenute come residui negli strati di epoca imperiale. Significativa anche la presenza di alcuni frammenti ceramici di epoca etrusca tra $\mathrm{i}$ quali un piede di forma chiusa in bucchero nero, qualche parete in impasto rosso bruno e poche tegole in impasto di I fase che documentano una forma di frequentazione dell'area già in epoca arcaica, nell'ambito del VI secolo a.C. In conclusione, l'edificio in corso di scavo presenta tracce di una frequentazione protrattasi per circa cinque secoli tra l'epoca romana repubblicana e quella imperiale. I materiali ceramici e numismatici finora rinvenuti consentono di ipotizzare che la primitiva costruzione possa essere realmente avvenuta nella seconda metà del III secolo a. C. o, al più tardi nel II, forse intorno alla metà, come sembrano testimoniare diversi assi della nota serie della prua della nave tra i quali uno pertinente ad una emissione della gens Sempronia, datato 172-151 a. C., uno della gens Saufeia del 152 a. C. e uno della Atilia del 148 a.C. Dopo le successive fasi di vita che appaiono ben documentate, tra il I secolo a. C. e il II secolo d.C., il termine ultimo per la vita all'interno del complesso è fissato dalla presenza di alcune ceramiche africane da cucina e da diverse monete emesse sotto l'imperatore Commodo, tra il 183 e il $189 \mathrm{~d}$. C., da un sesterzio di Settimio Severo del 197-198 d. C. e infine soprattutto da un sesterzio dell'imperatore Alessandro Severo, coniato nel $231 \mathrm{~d}$. C. Alla luce dei dati disponibili è verosimile che l'edificio sia stato abbandonato a partire dalla metà del III secolo d. C., al più tardi alla fine dello stesso o nei primi decenni del IV quando tra i ruderi del balneum venne sepolto un bambino, all'interno di un'anfora tipo africana tarda.

\section{Zona A, settore 2 : l'edificio quadrato. La ceramica e altro materiale (Luca Desibio)}

91 L'analisi del materiale archeologico rinvenuto all'interno dell'edificio a pianta quadrata consente, allo stato attuale, di confermare la lunga continuità di vita di tale edificio che, dal III sec. a. C. sembra giungere fino al III sec. d. C. Durante l'ultima campagna di scavi è stata rinvenuta una cospicua quantità di framenti riferibile alla classe ceramica a vernice nera ed un frammento in bucchero che attualmente rappresenta l'elemento di più antica datazione fin'ora qui rinvenuto.

La classe della ceramica comune appare sempre ben rappresentata da diversi frammenti riferibili ad altrettante forme ceramiche: va segnalato, in particolare, il rinvenimento della porzione superiore di una brocca databile tra gli ultimi decenni del III e gli inizi del II sec. a. C. (fig. 17), rinvenuta all'interno dell'Ambiente 11. Questo reperto giaceva all'interno dell'US 13, unità stratigrafica individuata al di sotto di una fistula plumbea che collegava l'Ambiente 11 con l'Ambiente 7. 
Fig. 17 - Castrum Novum. Bollo in planta pedis recante iscrizione.
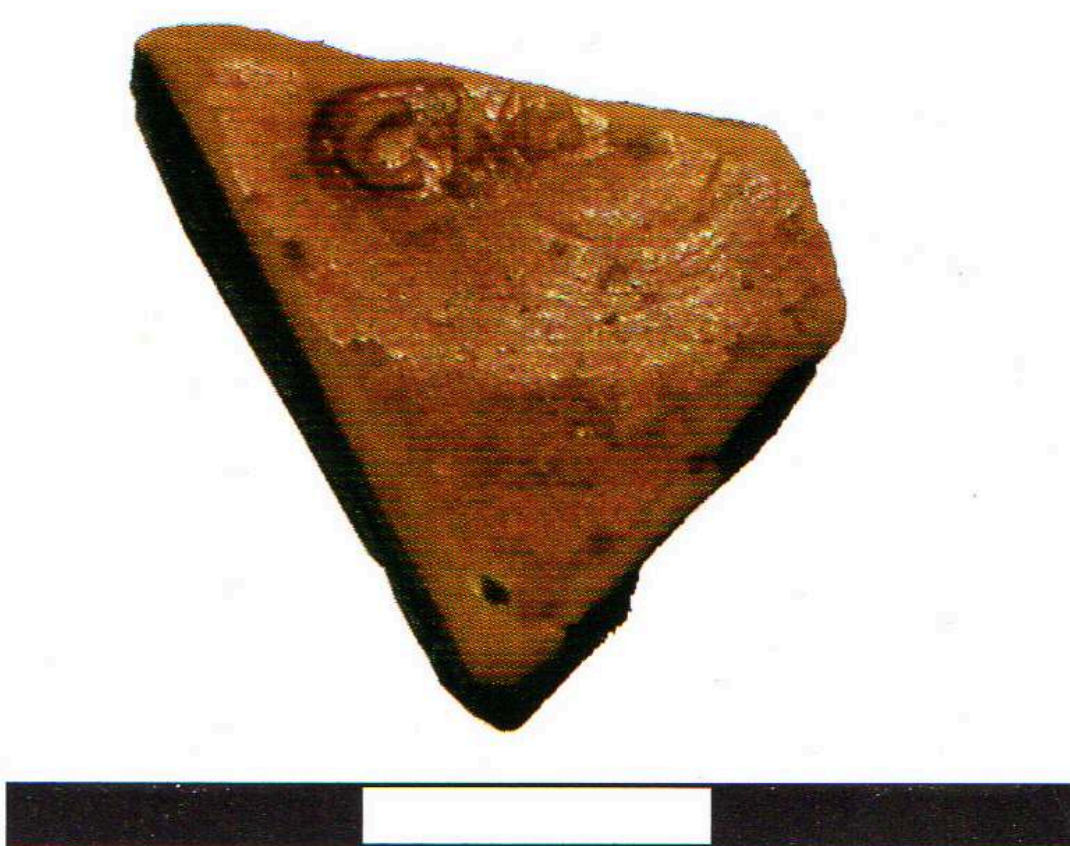

L. DESIBIO.

93 All'interno di questi due ambienti, inoltre, è stata rinvenuta la più alta percentuale di frammenti di ceramica comune acroma. Dall'Ambiente 7, corrispondente forse all'area di un portico, provengono due frammenti di piatto coperchio databili tra la fine del III ed il I sec. a. C., l'orlo di un'olla di epoca tardo-republicana ${ }^{53}$ ed un frammento di pentola dell'età augustea in uso fino all'epoca di Traiano.

La presenza della classe ceramica della sigillata italica appare testimoniata dal rinvenimento di pochi frammenti, recuperati per la maggior parte lungo il versante nord dell'edificio, tra i quali spicca un piccolo frammento dalla forma incerta sul quale è presente un bollo in planta pedis recante l'iscrizione C.ME[---], sulla base del quale è stato possibile ipotizzare una datazione generica verso la metà del I sec. d. C. Sempre dall'Ambiente 7 proviene un frammento di orlo di coppa in terra sigillata italica riferibile alla forma Goudineau 39, databile ai primi anni del I secolo a. C. ${ }^{54}$.

All'interno di questo settore la classe ceramica più rappresentativa (almeno da un punto di vista quantitativo), è quella della ceramica da cucina africana a patina cenerognola.

Dagli Ambienti 7 e 8 (US 5) provengono alcuni orli appartenenti prevalentemente alla forma della casseruola e del piatto coperchio, databili tra la fine del II ed il IV sec. d. C.

L'US 5 appare composta da notevoli quantità di frammenti di materiale da costruzione e ceramica misti a terra : tra i materiali recuperati al suo interno sono da segnalare un'ansa di un'anfora Dressel 20 ed un frammento di bollo laterizio orbicolare del quale è visibile solamente la parte sinistra recante l'iscrizione [ex]FIG.caes [---](fig. 18). 
Fig. 18 - Castrum Novum. Frammento di mattone con bollo.

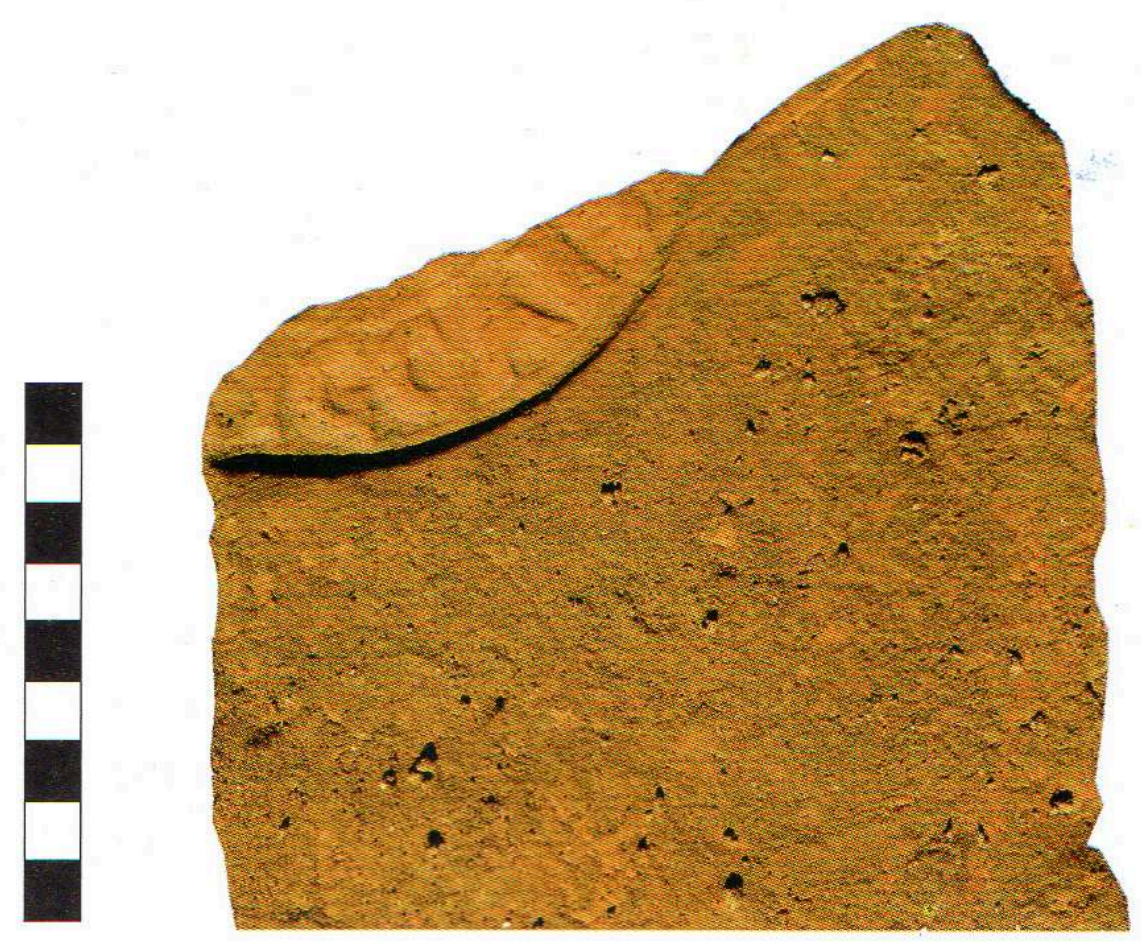

L. DESIBIO.

Durante le fasi finali relative all'ultima campagna archeologica, le attività di scavo si sono concentrate prevalentemente all'interno degli Ambienti 2, 4 e 5.

Lo scavo degli Ambienti 2 e 4 in particolare ha riservato alcune interessanti sorprese. Dall'Ambiente 2, oltre ad una notevole quantità di monete databili tra il III sec. a. C. ed il II-III sec. d. C..$^{55}$, è stato recuperato un congruo numero di frammenti di ceramica a vernice nera, ceramica sigillata italica ed il frammento di bucchero sopra menzionato.

L'Ambiente 4, ha restituito invece alcuni reperti ceramici quasi integri come piatti in ceramica comune e coperchi mentre dagli strati sottostanti, è emersa quella che sembra essere una canaletta di scolo forse riferibile ad una cucina. L'Ambiente 7 continua a restituire frammenti di ceramica da cucina africana, mentre dall'Ambiente 10 proviente una cospicua quantità di frammenti di ceramica in terra sigillata. La prosecuzione delle attività di scavo a ridosso dei vari ambienti, ha portato all'individuazione della parte inferiore di un'anfora e di un fondo di dolio ubicati agli angoli delle strutture murarie rispettivamente degli Ambienti 5 e 7. È probabile che questi avessero lo scopo di captare le acque piovane o comunque di svolgere la funzione di grandi contenitori di acqua, forse con qualche relazione con l'attività lavorativa che si svolgeva tra gli ambienti 7 e 11.

Come detto all'inizio di questo contributi, l'edificio presenterebbe una lunga continuità di vita di almeno sei secoli.

Tuttavia, l'analisi del materiale ceramico insieme allo studio del materiale numismatico e quello delle strutture superstiti, permette di avanzare alcune ipotesi circa una probabile diversa fruibilità delle strutture durante i secoli. 
103 Non sarebbe da escludere, infatti, che alcuni ambienti possano aver avuto una durata di vita più lunga di altri o una diversa destinazione d'uso, con l'abbandono di alcuni ambienti già durante il I ed il II secolo $\mathrm{d}$. $\mathrm{C}$.

104 Se è vero, come sembra, che la pianta dell'edificio quadrato a nostra disposizione ricondurrebbe allo schema di una domus romana di epoca repubblicana, è altrettanto vero che le strutture poste a nord (Ambienti 1, 3, 6, 7, 11 ed area 9) sembrano aver subito evidenti modifiche strutturali, segno di una continuità d'uso attraverso i secoli.

105 Tuttavia le recenti attività di scavo hanno permesso di ipotizzare una lunga continuità di vita anche per gli Ambienti 10, 2 e 4.

Le prossime campagne di scavo offriranno forse, la possibilità di comprendere meglio le dinamiche ed i cambiamenti strutturali avvenuti attraverso i secoli all'interno di questo edificio ed apporteranno nuovi spunti di ricerca.

\section{Zone B : la stratigraphie côtière (G. Poccardi)}

107 Le site antique de la colonie maritime du peuple romain de Castrum Novum localisé au nord de la commune de Santa Marinella possède une ligne de côte qui abrite une stratigraphie de plus de $200 \mathrm{~m}$ de long où sont visibles, au nord (secteur 2), les restes d'édifices de la ville romaine et, au sud (secteur 1) des niveaux qui sont datables principalement de l'âge du Fer ou villanovien ( $\mathrm{X}^{\mathrm{e}}$ ou IX $\mathrm{I}^{\mathrm{e}}$ siècles). Depuis 2010, dans le cadre de la mission archéologique italo-française, une étude approfondie a été entreprise sur ce document stratigraphique exceptionnel (fig. 19 et fig. 20). 
Fig. 19 - Photographie de Castrum Novum (google earth) avec délimitation des différents secteurs et sous-secteurs.

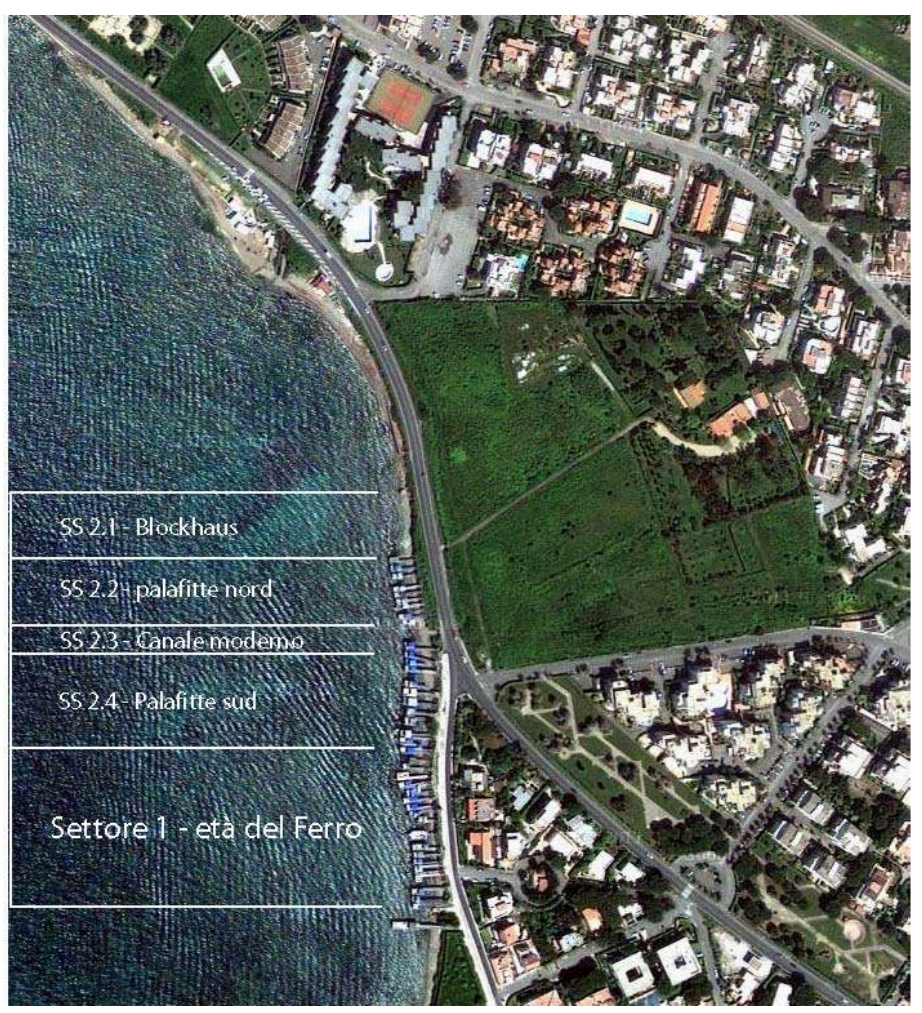

G. Poccardi.

Fig. 20 - Vue de la partie nord de la stratigraphie depuis le large.

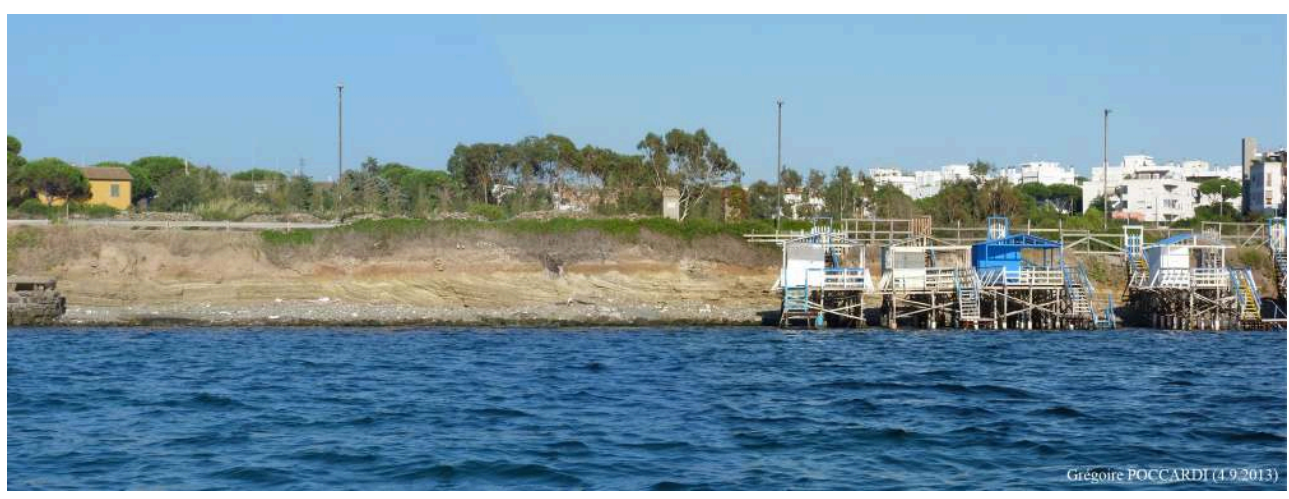

G. Poccardi

\section{Les objectifs et les détails des opérations de la campagne de septembre 2013}

Les trois premières campagnes d'étude ont permis d'effectuer les relevés stratigraphiques et planimétriques et de procéder à une couverture photographique de la partie « romaine » de la stratigraphie. Les trois semaines de campagne en septembre 2013 ont été consacrées à achever le travail de terrain et de vérification documentaire de ce secteur. 


\section{La structure $\mathrm{n}^{\circ} 17$}

109 Durant la campagne précédente de septembre 2012, en raison de nombreux jours de mauvais temps, nous n'étions pas parvenus à terminer le travail de relevé des structures visibles dans le sous-secteur 3 - canal moderne. Pour cette raison, nous avons pris la décision de nettoyer à nouveau l'imposante structure de soutènement $\mathrm{n}^{\circ} 17$ avec paroi occidentale en opus reticulatum afin de dessiner la coupe transversale est-ouest (CN 2013B-1) et de compléter la section nord-sud non achevé (planche CN 2012B-3b) l'année précédente (fig. 21).

Fig. 21 - Castrum Novum. Coupe transversale de la structure $n^{\circ} 17$ (planche CN 2013B-1).

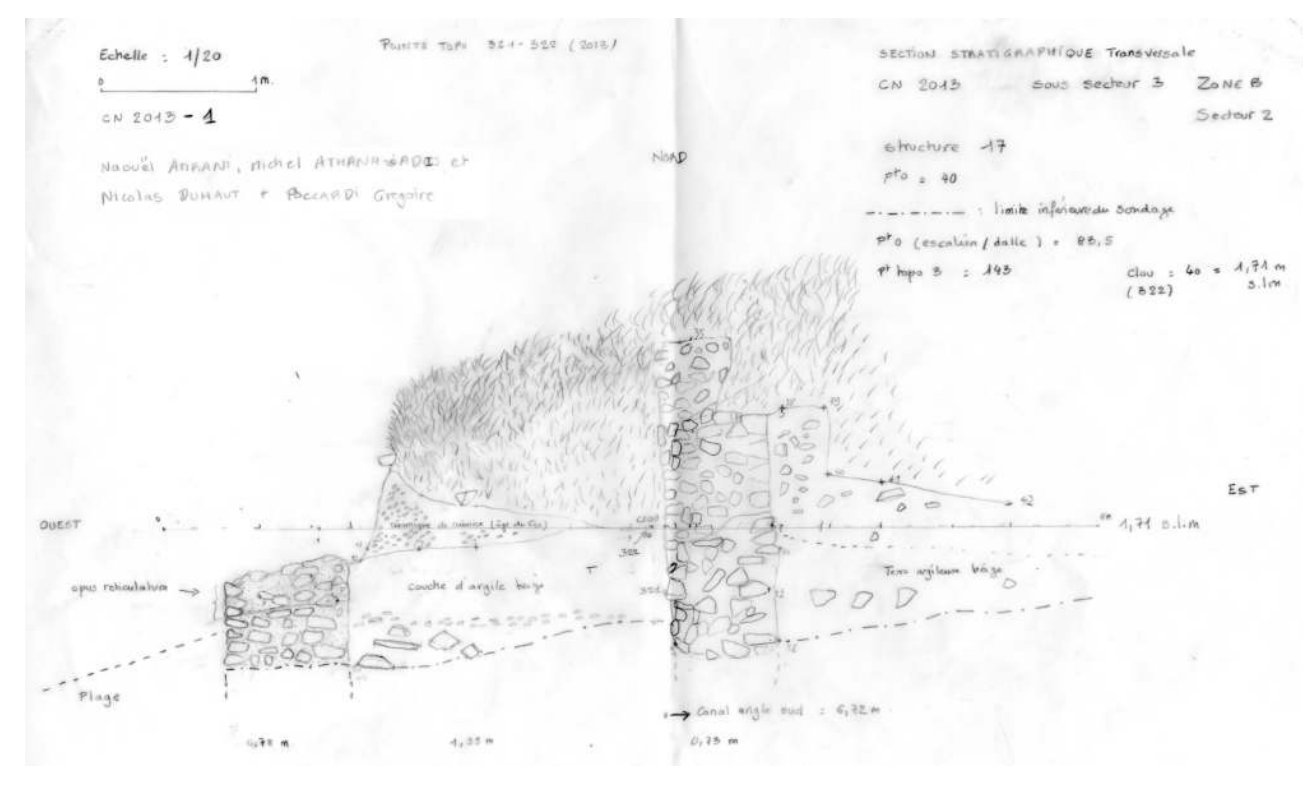

G. Poccardi.

110 Nous avons profité de cette opportunité pour vérifier les points topographiques et faire de nouvelles photographies de la structure (fig. 22). 
Fig. 22 - Castrum Novum. Photographie de la structure $n^{\circ} 17$ (c-d-e-f) après le nettoyage du sable et des galets.

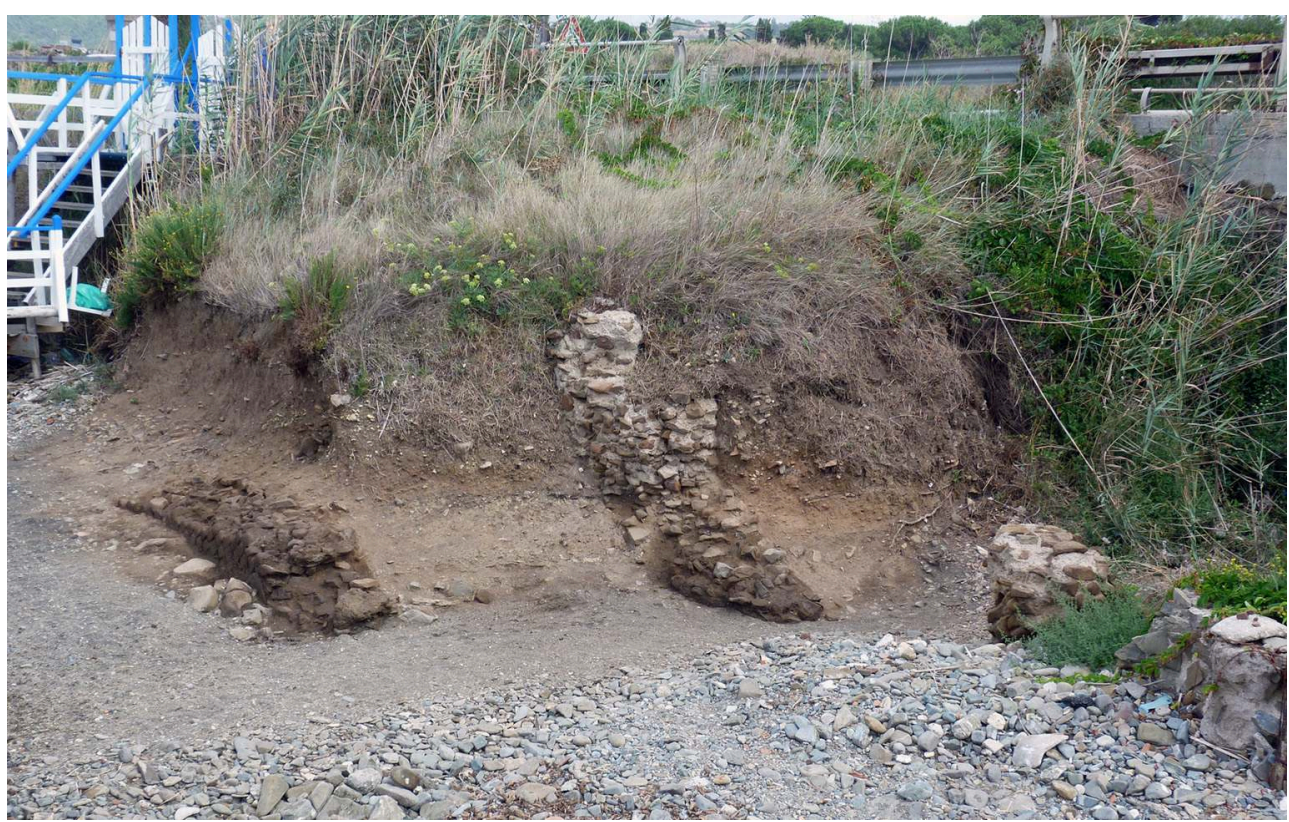

G. Poccardi.

\section{La topographie dans le cadre du secteur 2}

111 Le travail de topographie a été effectué sous la responsabilité de Véronique Picard pour les deux premières semaines, puis de l'architecte Nathalie André (IRAA - USR 3155 du CNRS, Université de Pau et du pays d'Adour) pour la troisième semaine. Dans le cadre de la section stratigraphique côtière, elles sont intervenues pour :

- placer de nouveaux point topographiques aux niveaux de la via dei Marconi en prévision de l'étude de la partie villanovienne de la section stratigraphique, un des objectifs de la prochaine campagne de 2014 (fig. 23). Dès l'automne 2013, un petit groupe composé de Valentina Asta et Marco Fatucci (Gruppo Archeologico del Territorio Cerite) a fait les premiers relevés de ces niveaux d'occupation, travail qui devra être amplifié et achevé lors de la prochaine campagne de 2014.

- procéder à un nouveau relevé et dessin de l'égout placé de biais $n^{\circ} 3$ (structure $n^{\circ} 5$ ) dans le sous-secteur 1 afin de l'introduire correctement dans le document général de la section stratigraphique (fig. 24).

- placer de nouveaux points topographiques sur les structures quand cela était possible : la présence des poteaux de bois des cabanons rendant difficile l'acquisition de certains points sur la stratigraphie. 
Fig. 23 - Castrum Novum. Visée d'un point topographique situé via di Marconi depuis la plage.

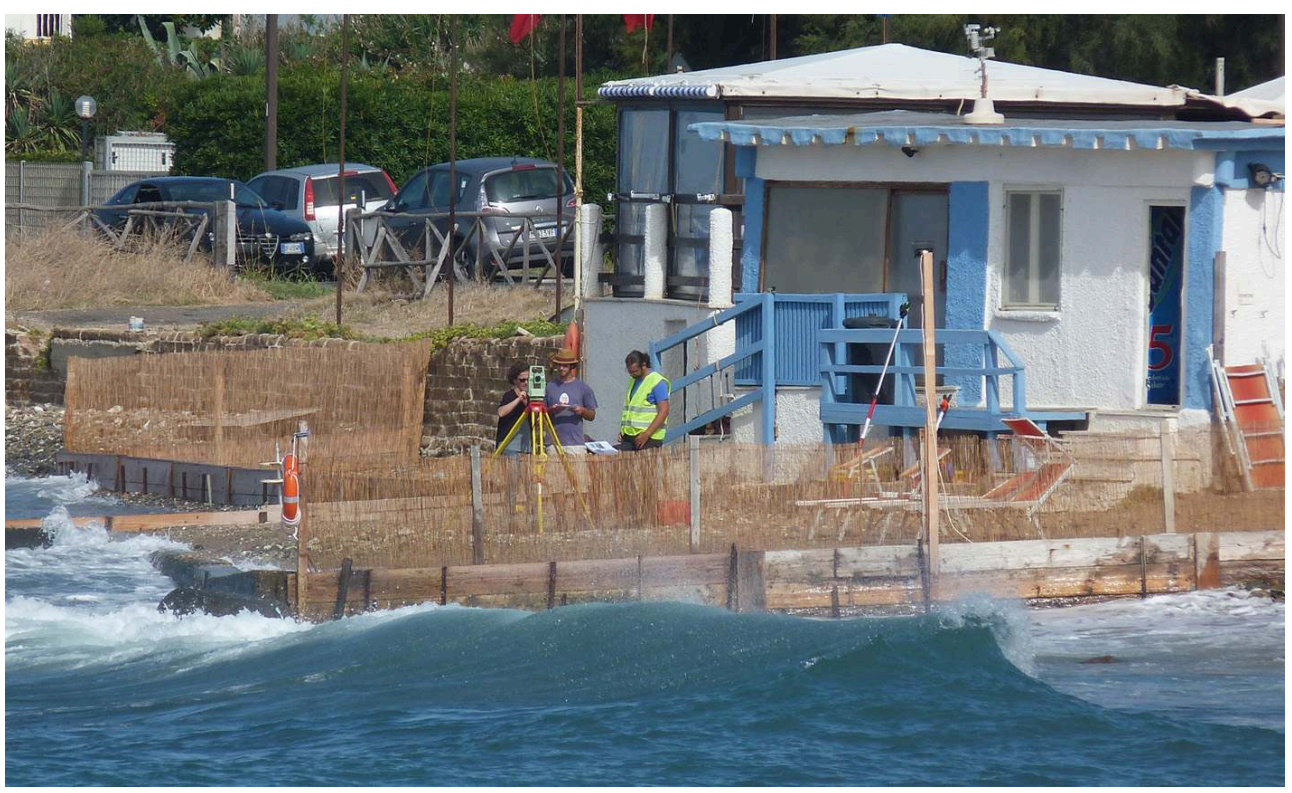

G. POCCARDI.

Fig. 24 - Castrum Novum. Égout de l'époque impériale $\mathrm{n}^{\circ} 3$ avec le cadre $(1 \times 1 \mathrm{~m}$.) pour le dessiner avec des points topographiques.

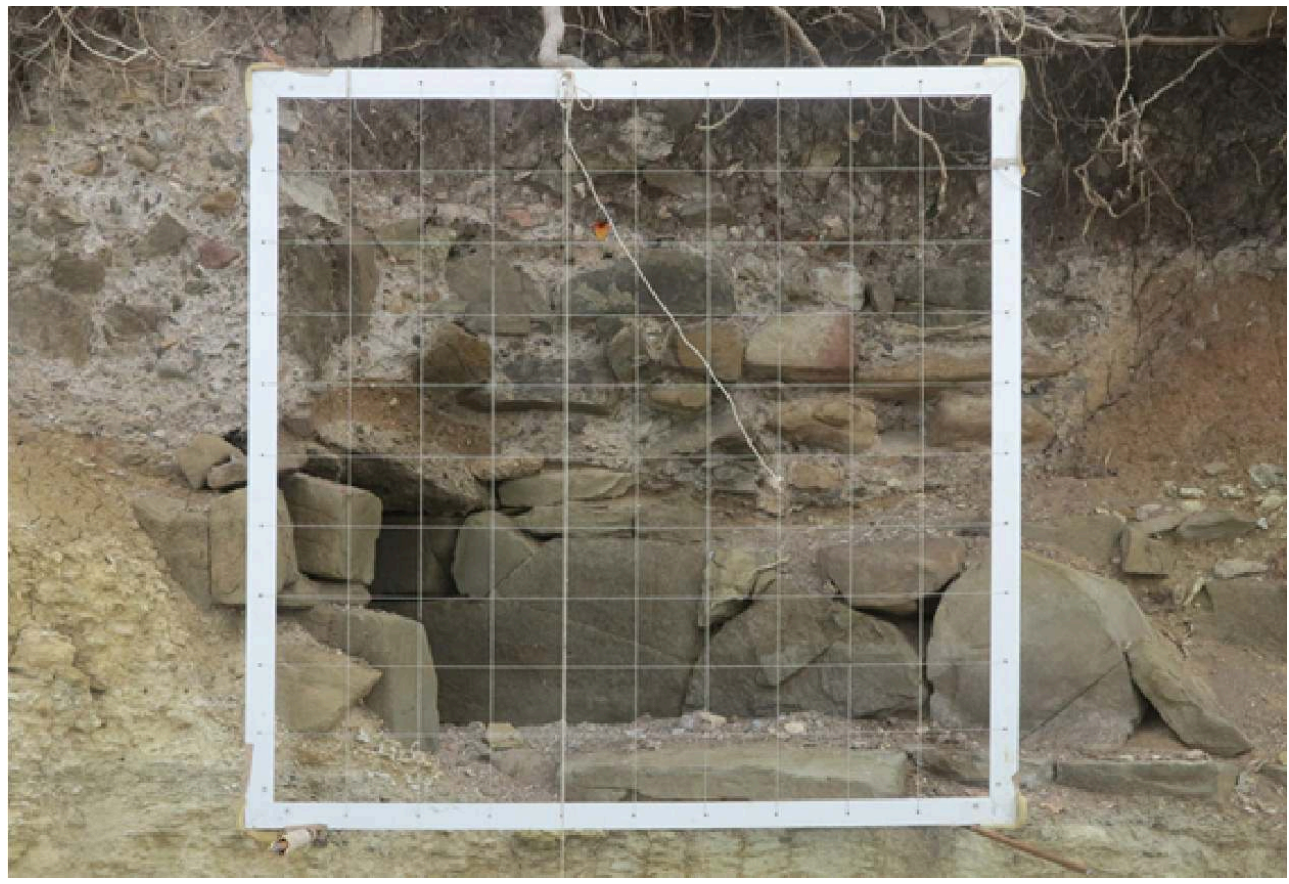

G. Poccardi.

\section{Vérification de la documentation existante}

112 L'importante documentation accumulée les trois années précédentes a impliqué de réaliser un travail de vérification sur le terrain d'un certain nombre de relevés afin de s'assurer de leur exactitude avant de les introduire in fine sur le document Autocad en 
cours d'élaboration par Nathalie André et Véronique Picard (voir fig. 14 de la chronique de la campagne de septembre 2012).

Il s'est agi de reprendre les dessins de certains murs, après la vérification de l'exactitude de leur position (côte et mesures en hauteur comme en largeur). Ce travail de vérification a permis de voir, par exemple, que la structure $n^{\circ} 10$ était en réalité deux murs différents s'appuyant l'un sur l'autre ou encore que la structure $n^{\circ} 13$, qui avait été interprétée à tort comme deux murs distincts superposés, était en réalité un mur unique avec sa fondation (13a et 13b), ce qui provoque des modifications dans la numérotation d'un certain nombre de structures (fig. 25).

Fig. 25 - Castrum Novum. Planche CN 2011B -16 b dans le sous-secteur 2 après reprise du document.

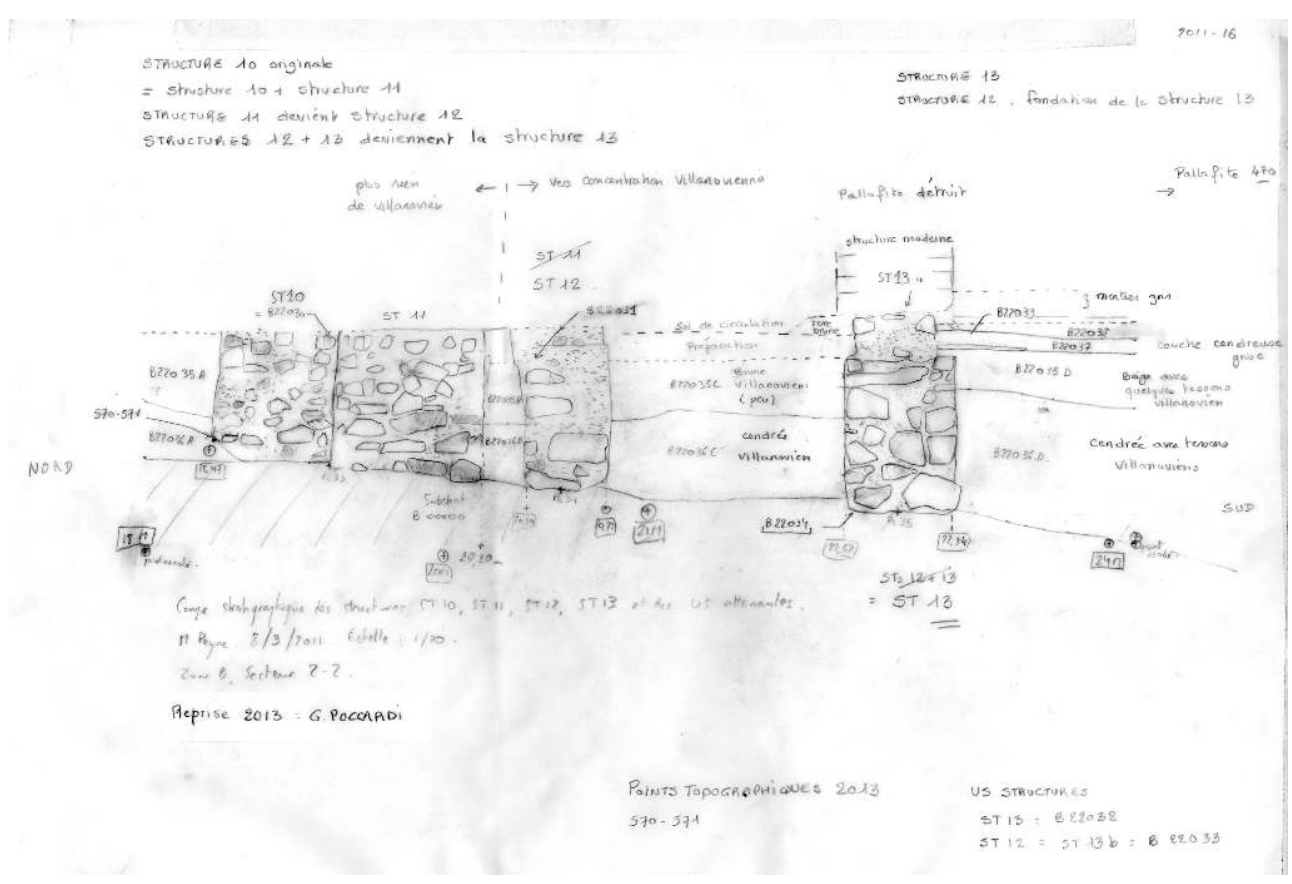

G. Poccardi.

114 Ce travail de vérification a aussi permis de reprendre l'étude des liens stratigraphiques entre les structures visibles pour une question de clarté. Le principal résultat de cette analyse montre que, dans la partie méridionale de la ville, les Romains avaient creusé les fondations de leurs édifices dans des strates plus anciennes comportant de la céramique de l'époque villanovienne et que la densité du matériel de cette période diminue en allant vers le nord pour disparaître complètement milieu du sous-secteur 2 . Cela signifie, tout d'abord, que la colonie se serait implantée ex nihilo, car la stratigraphie ne montre aucune trace d'une éventuelle occupation datant de la période étrusque (VII ${ }^{\mathrm{e}}-\mathrm{III}^{\mathrm{e}}$ siècles av. J.-C.) ; ensuite qu'elle s'est implantée dans une ancienne zone d'occupation du début du I $^{\text {er }}$ millénaire av. J.-C. avec chevauchement de deux établissements, mais sans lien direct entre eux.

Il s'est agi enfin de noter les changements intervenus sur la section, en particulier, dans le cadre des dommages provoqués par les récentes tempêtes. Par exemple, la fondation du mur $n^{\circ} 7 \mathrm{~h}$ a été détruite pendant l'hiver dernier par l'écroulement localisé de la paroi, mais sa destruction a permis de faire apparaître un élément d'un autre mur construit en briques. 


\section{La « maigre » récolte de matériel}

Enfin, si l'étude de la stratigraphie implique aucune intervention de fouille sur la section, du matériel peut toutefois tomber de la paroi ; hors contexte, il n'en donne pas moins des informations :

élément d'une fibule de bronze de l'âge du Fer retrouvé devant la structure $\mathrm{n}^{\circ} 17 \mathrm{c}$, certainement tombée des niveaux archéologiques encore en place à ce niveau. fragment de tuile avec un timbre anépigraphe découvert devant l'égout de l'époque impériale $n^{\circ} 2$ dans le sous-secteur 1 .

\section{Les résultats concrets de 2013 et les perspectives pour 2014}

117 Cette étude a été essentielle pour sauver une documentation archéologique en péril constant face aux aléas naturels. Les tempêtes hivernales et le mauvais temps du printemps ont considérablement endommagé les parois avec la destruction de structures bien conservées jusqu'ici comme l'égout $n^{\circ} 1$ ou une partie de la section dans le sous-secteur 2 au nord de l'égout $n^{\circ} 4$ de l'époque impériale. Dans peu de temps, en raison de la proximité de la via Aurelia (SS1), il sera nécessaire d'entreprendre des travaux de consolidation dans la partie nord de la stratigraphie par l'édification d'un mur de soutènement pour éviter que la route nationale 1 ne soit emportée par la mer.

118 L'objectif principal de la prochaine campagne sera donc d'achever l'étude de l'ensemble de la stratigraphie par le traitement du secteur 1 « protohistorique » en contrebas de la via dei Marconi, vers le Capo Linaro qui est lié étroitement au secteur " romain ».

119 L'autre objectif programmé de la prochaine mission sera la réalisation d'un document orthophotographique de l'ensemble de la stratigraphie. Cette opération sera confiée à Aurélia Lureau, étudiante à l'Université de Paris I-Panthéon Sorbonne, qui a commencé un Master 1 sur l'utilisation des nouvelles technologies en archéologie. De passage en Italie, elle est venue une journée sur le chantier pour réaliser une série de photographies sur une portion limitée de la stratigraphie, au niveau de l'égout $n^{\circ} 3=$ Structure $n^{\circ} 5$ dans le sous-secteur 1 , qu'elle a ensuite traité à son retour avec un logiciel permettant ainsi de créer un document photographique en trois dimensions de la portion choisie. Celui-ci sera ensuite intégré dans le dossier Autocad géré par Nathalie André.

120 Enfin, signalons aussi la visite de Marco Anzidei et Alessandra Benini (membres de l' Istituto di Geologia e di Vulcanologia da Roma), visite qui permet de voir, qu'au-delà de son intérêt archéologique, la stratigraphie côtière est aussi un document géologique d'une haute valeur scientifique.

\section{Zona C : la ceramica dal fondale di Capo Linaro (Luca Desibio)}

L'attivita di ricerca subacquea svolta negli ultimi anni dal Centro studi marittimi nella baia di Castrum Novum che da Capo Linaro doveva giungere sino al fosso de «le Guardiole ", ha portato all'individuazione e al rinvenimento di materiale archeologico di notevole qualita e fattura. 
122 I reperti provengono principalmente, dal tratto di spiaggia corrispondente alla baia e naturalmente dal mare dove sono state avvistate diverse "matte " (costituite da zolle dure di sabbia e limo compattati dallo sviluppo delle radici dell'alga della poseidonia) e cumuli di materiale archeologico a profondità che raggiungono anche i dieci metri.

123 I reperti, nonostante la presenza di concrezioni, appaiono in buono stato di conservazione. La ceramica a vernice nera appare ben attestata, in questo caso, da almeno due reperti molto ben conservati : una coppa con anse a doppio bastoncello della forma Morel $3131 \mathrm{~b} 1^{56}$, conservata per quasi la meta e databile al II secolo a. C. (fig. 26) e una coppa rinvenuta quasi integra della forma Morel $2323^{57}$ databile alla prima meta del II secolo a. C.

Fig. 26 - Castrum Novum. Coppa in ceramica a vernice nera con anse a doppio bastoncello.

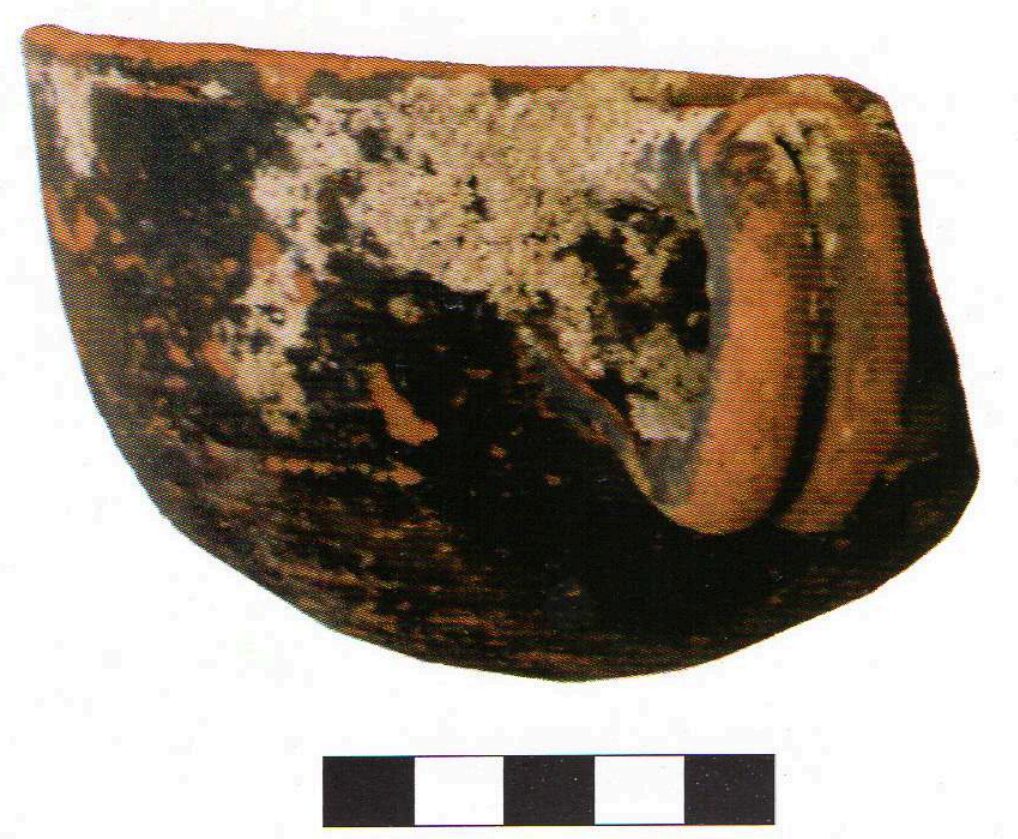

L. DESIBIO.

La presenza della ceramica sigillata (fig. 27) è testimoniata da tre reperti (di cui due in buono stato di conservazione rinvenuti per circa la meta della loro forma) che sembrano rappresentare al momento, l'aspetto forse piu interessante nel panorama ceramico e commerciale di questo sito per la loro provenienza e tipologia. 
Fig. 27 - Castrum Novum. Coppa in terra sigillata italica.

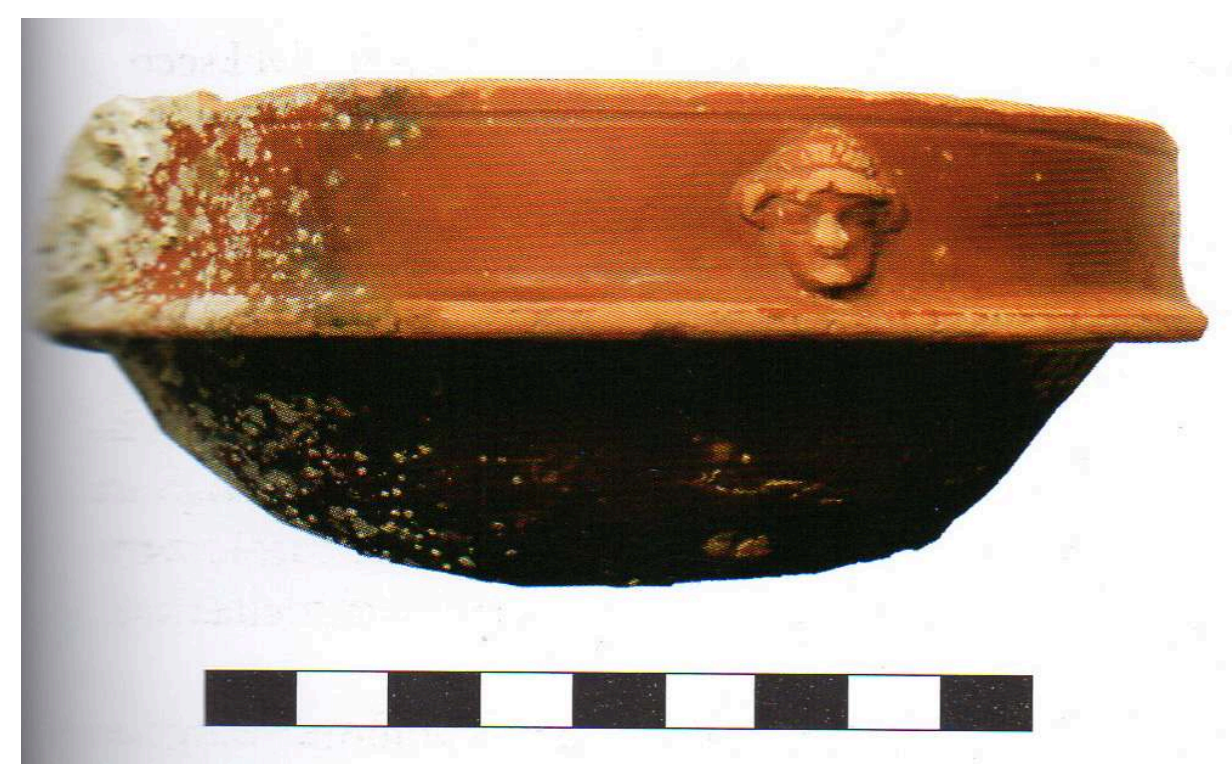

L. DESIBIO.

I primi due in particolare, meglio conservati, sono riconducibili alla forma della coppa : la prima, in terra sigillata sud-gallica, assimilabile alla forma Dragendorff $36^{58}$ databile al I-II secolo d. C. ; la seconda, una forma tarda di terra sigillata nord-italica vicina alla forma Dragendorff $24 / 25$ tipo $\mathrm{A}^{59}$, che risulta inquadrabile cronologicamente nella prima meta del I secolo d. C.

Il restante materiale recuperato e costituito prevalentemente da reperti appartenenti alla classe della ceramica comune. Tra questi una parete di olla con ansa a nastro databile alla seconda meta del II secolo a. C., un'ansa con parte dell'orlo impostato alla sommita di essa riferibile ad una brocca-bottiglia del I secolo a. C. ed un orlo di olla sempre del I secolo a. C.

Infine lungo la costa pertinente alla baia portuale è stato rinvenuto un elemento decorativo in marmo (una piccola antefissa ?) del tipo a palmetta, di notevole interesse, ma al di fuori del contesto ceramico (fig. 28). 
Fig. 28 - Castrum Novum. Frammento architettonico in marmo con motivo a palmetta.

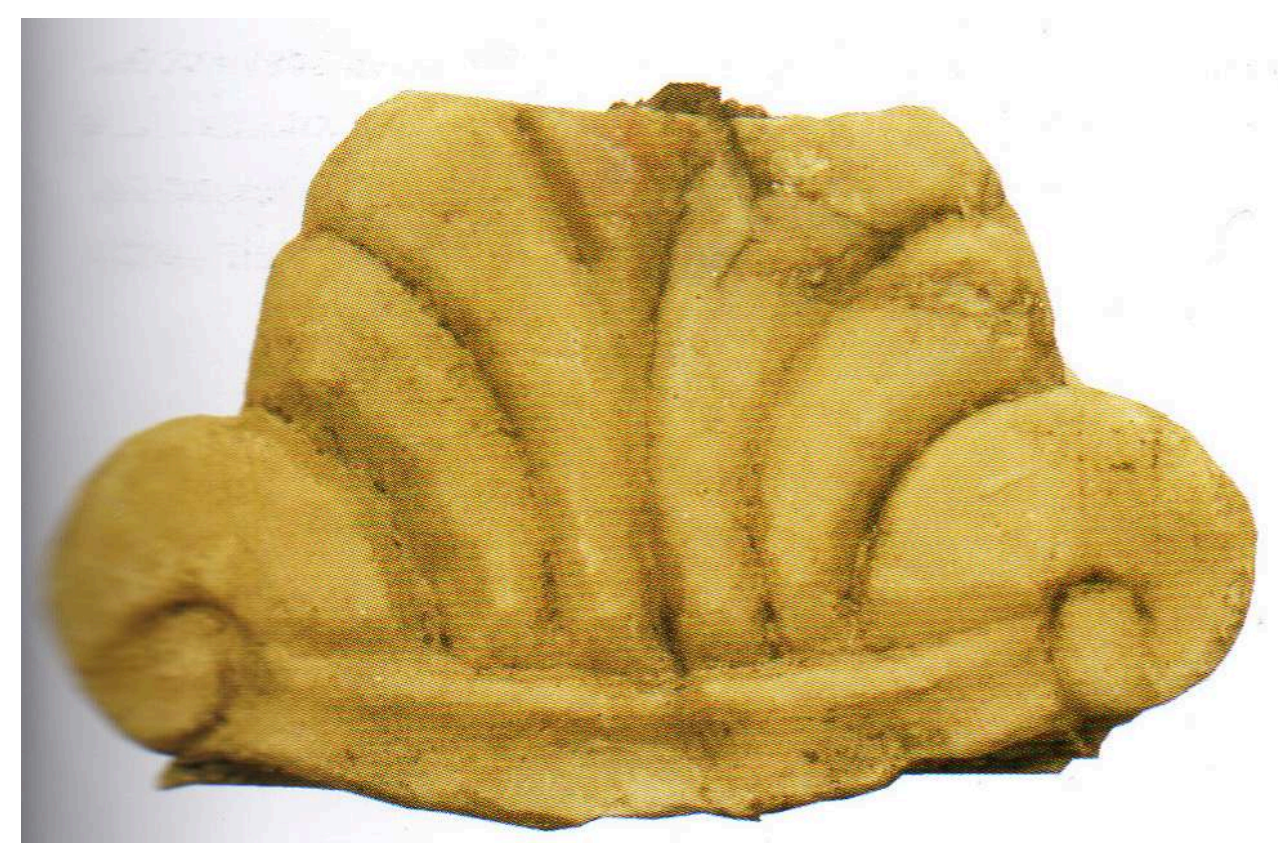

L. DESIBIO.

Le ultime e più recenti attivita di ricognizione subacquee, infine, hanno portato all'individuazione di ulteriori reperti appartenenti, genericamente, alla classe ceramica della terra sigillata e la presenza di bolli di diversa tipologia su alcuni di essi rappresenta un punto di partenza molto importante per un futuro studio sulle relazioni commerciali dell'antica Castrum Novum.

\section{Breve contributo per l'aggiornamento della carta archeologica di Castrum Novum in località « Prato Cipolloso ${ }^{60}$ (Massimiliano Galletti)}

Il presente contributo ${ }^{61}$ verte su alcune scoperte fortuite effettuate dallo scrivente, nel settembre 2013, che vanno ad integrare i dati offerti dalla cartografia archeologica della Forma Italiae inerenti il territorio della colonia marittima romana di Castrum Novum, editi da Pier Alfredo Gianfrotta nel $1972^{62}$.

Il sito in questione occupa uno spuntone di calcare marnoso emergente in più punti, sul versante orientale della «Valle del Marangone » a circa $600 \mathrm{~m}$ dal fosso omonimo ${ }^{63} . \mathrm{Si}$ segnala in particolare un'area di frammenti fittili, estesa per circa $200 \mathrm{mq}$, su terreno in leggera pendenza con copertura erbosa dove si rinvengono: numerosi frammenti di tegole e coppi romani, diversi frammenti di ceramica comune repubblicana e imperiale, qualche frammento di ceramica campana, di dolia e di anfore. Tra i materiali in superficie appaiono anche schegge di arenaria, di peperino e pietrame locale di piccola e media pezzatura, ma soprattutto, un residuo della parte superiore (catillus) di una piccola macina granaria a mano in pietra lavica (mola trusatilis). Lo stesso materiale fittile e lapideo compare reimpiegato nei due lati di una macera che s'incontrano ad angolo retto a delimitare parzialmente l'area in oggetto, ed è chiaramente visibile 
specie nel crollo di un tratto di questo muricciolo a secco composto da pietre reperite in loco. In modo particolare risalta un blocco di scaglia ( $\mathrm{cm} 37 \times 22 \times 13)$ inserito nel lato che scende verso la vallata summenzionata. È ancora, non più nella sua collocazione originaria spicca quella pietra denominata lapis pedicinus dagli agronomi latini, che si presenta in un blocco di arenaria con una frattura che investe parte di un lato corto, ricavato da un'ara di torcular presumibilmente dopo la rottura parziale di quest'ultima (fig. 29).

Fig. 29 - Castrum Novum. Lapis pedicinus creato riusando la base di un torchio.

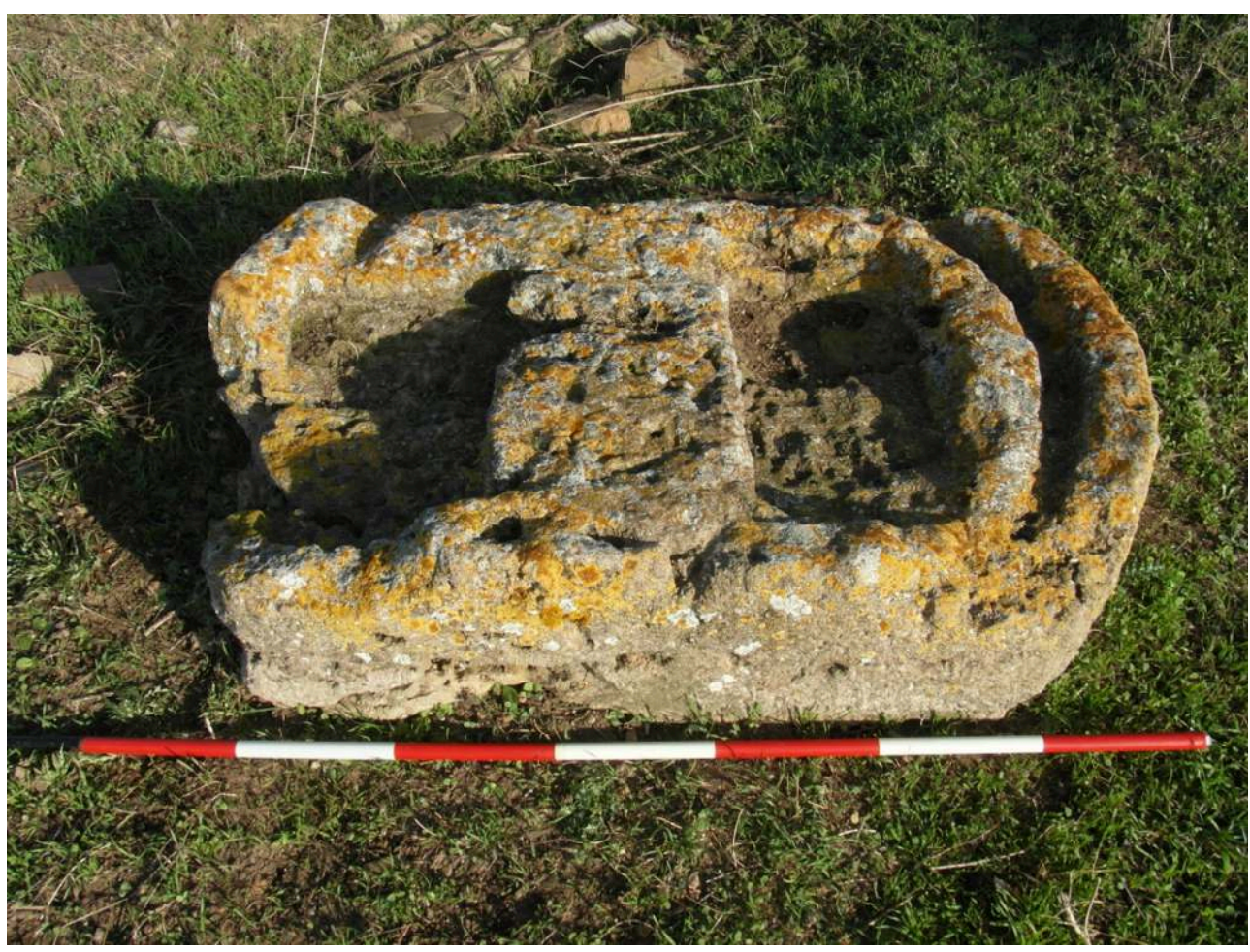

M. GALLETTI.

131 Occorre quindi precisare riguardo alle sue dimensioni (m 1,33 x 0,85 x 0,30) : la misura maggiore corrisponde al diametro della base di pressa, in origine circolare e recante ancora le tracce del canaletto per il deflusso del liquido di spremitura. Sono poi evidenti i due incassi di forma rettangolare (ca $\mathrm{cm} 25 \times 50$ ), distanti tra loro $\mathrm{cm} 32$ e aventi una profondità di almeno $\mathrm{cm} 10$. Come è noto, tali incassi (foramina) servivano per l'alloggiamento dei travi verticali del torchio (arbores), che a loro volta sostenevano il trave pressore (prelum) ${ }^{64}$. I dati così acquisiti rimandano a un edificio rustico romano con tracce di frequentazione, cronologicamente inquadrabili dalla fine del periodo repubblicano alla tarda età imperiale ${ }^{65}$. La villa si poteva fondare sia sul banco geologico regolarizzato, sia su basamenti artificiali come suggeriscono alcuni brevi allineamenti affioranti orientati in varie dimensioni, larghi dai 40 ai $60 \mathrm{~cm}$, realizzati in grossi blocchi semilavorati di calcare locale, apparentemente privi di legante (fig. 30 ). 
Fig. 30 - Castrum Novum. Esempio di basamento che si congiunge al banco roccioso.

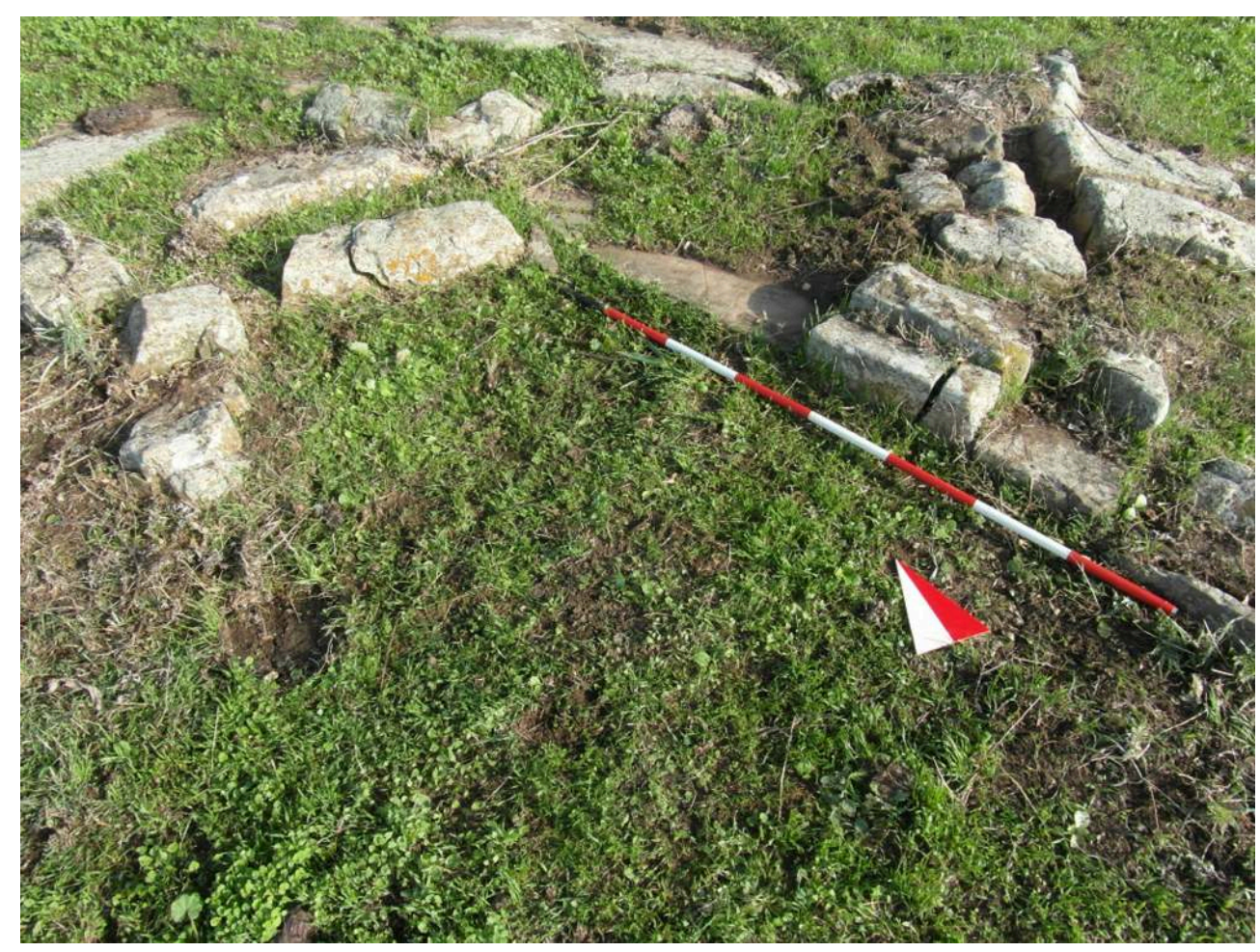

M. GALLETTI.

132 La presenza in superficie del pietrame suddetto senza alcuna traccia di malta cementizia, dovrebbe potersi collegare alle strutture in elevato legate con malta terrosa fino all'imposta della carpenteria del tetto ${ }^{66}$. Da segnalare, inoltre, il ritrovamento di una moneta raffigurante l'imperatore bizantino Giustiniano I (527-565). È un decanummo in bronzo coniato dalla Zecca di Roma (fig. 31), recante al dritto il busto frontale di Giustiniano con elmo piumato, corazza, scudo e globo crucigero nella destra, nonché la legenda in parte decifrabile nell'intorno : [..] IUSTINIANUS [---] ${ }^{67}$; mentre sul rovescio appare la lettera $\mathrm{I}^{68}$ tra due stelle a sei punte entro corona d'alloro (peso $4,9 \mathrm{gr}$, diametro $17 \mathrm{~mm})^{69}$. 
Fig. 31 - Castrum Novum. Decanummo di Giustiniano I.

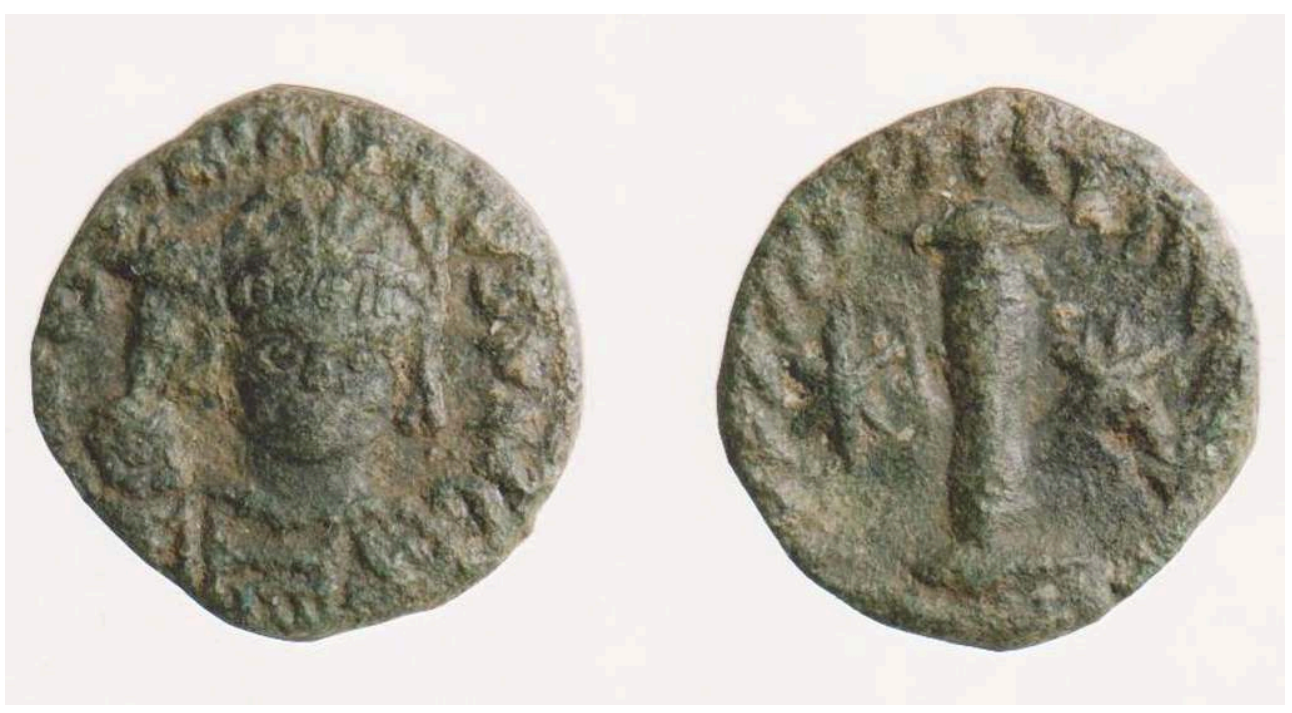

M. GALLETTI.

Esso rappresenterebbe perciò il termine di riferimento cronologico più basso della fattoria. Ulteriormente, questa testimonianza monetale finora unica nel comprensorio, fermo restando ovviamente il contesto di rinvenimento, potrebbe essere messa in relazione con gli eventi bellici che interessarono la città e il porto di Centumcellae, ampiamente noti grazie a diversi passi della narrazione di Procopio di Cesarea ${ }^{70}$. I fatti descritti dallo storico durante gli anni della guerra greco-gotica (535-553), sottintendono una presenza degli Ostrogoti e dei Bizantini anche nelle campagne circostanti il centro traianeo, al fine di mantenere in funzione o ripristinate gli impianti produttivi delle ville rustiche romane, e assicurare i rifornimenti di viveri alle truppe dislocate in zona, soprattutto quando veniva meno l'afflusso di viveri via mare. Il programma di allestimento delle difese costiere tirreniche portato avanti da Giustiniano, doveva favorire il porto di Centumcellae, in quanto costituiva l'avamposto strategico più rilevante a nord di Roma ${ }^{71}$. Va aggiunto che le indagini archeologiche svolte all'interno del Castello di S. Severa tra il 2003 e il 2009, hanno rimesso in luce strutture di epoca tardoantica-altomedievale fra cui una muratura "a telaio » di probabile tradizione bizantina ${ }^{72}$.

Poco distante dalla villa, circa $50 \mathrm{~m}$ a est, al di là del tratto crollato della ricordata macera fiancheggiata da una carrareccia, si ritrova in percentuale minore il materiale fittile sopra esposto come pure attorno alle rovine di una costruzione moderna posta nelle immediate vicinanze. Direttamente a sud si distingue una lieve depressione del terreno soggetta a un forte dilavamento, nella quale sopravvivono gli avanzi di una sepoltura appena emergenti dal piano di campagna (fig. 32). 
Fig. 32 - Castrum Novum. Resti della sepoltura.

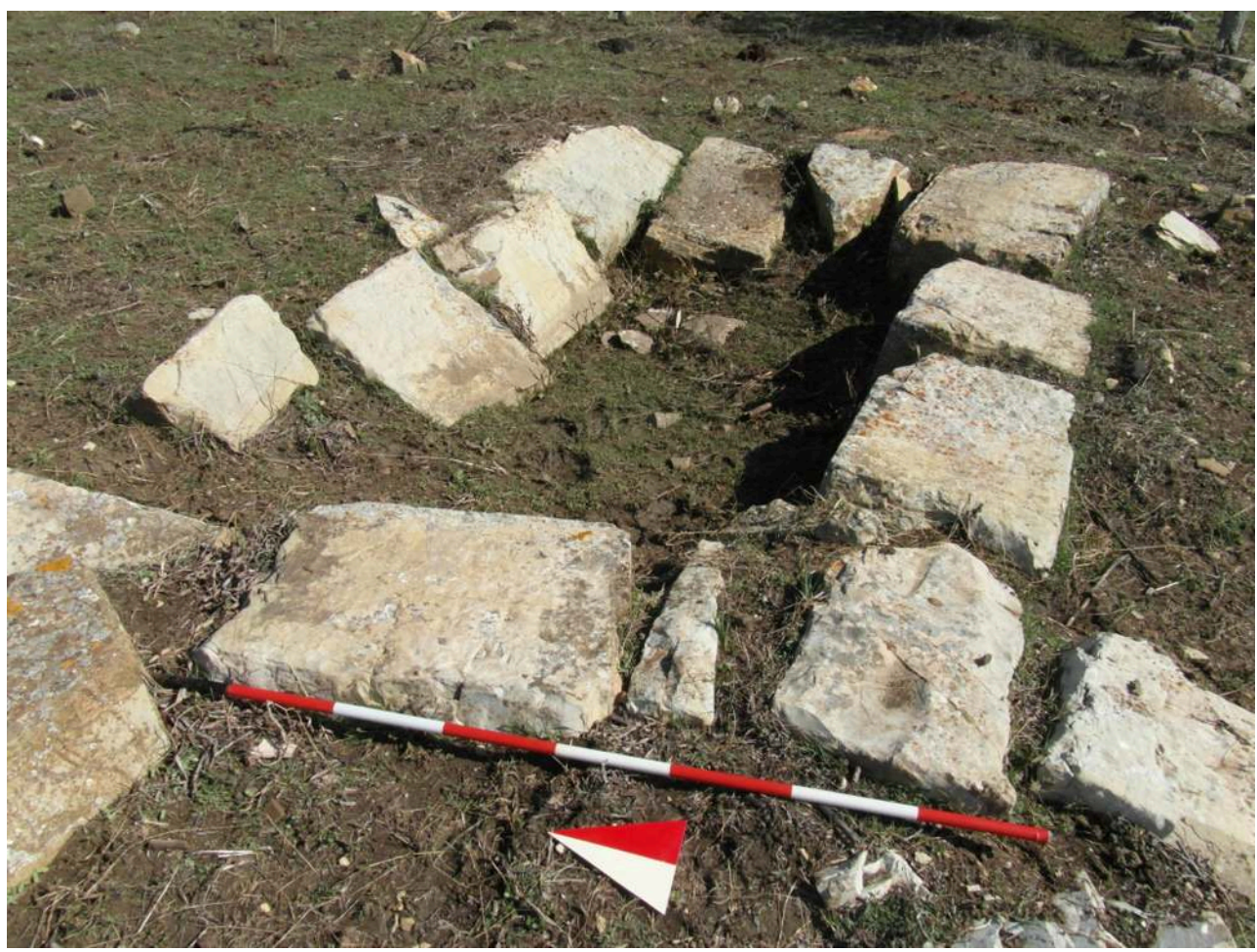

M. GALLETTI.

Si tratta di un ambiente rettangolare chiuso da tutti i lati (perimetro interno di $\mathrm{m} 2,50 \times 1,50$ ), con orientamento est-ovest, costituito da grossi blocchi di palombino grossolanamente squadrati e posti in opera a secco, dalle dimensioni approssimative di $\mathrm{cm} 80 \times 60 \times 40$, sebbene non manchino pezzi informi. Alcuni di essi sono slittati fortemente all'interno, che risulta interrato e vi è possibile scorgere solo un filare inferiore nel lato lungo sud; altri invece tendono a spanciare all'esterno. Intorno giacciono in un raggio di pochi metri altri elementi lapidei della stessa tipologia : le notizie raccolte sul posto riferiscono che molti anni fa la fossa era ricoperta in modo disordinato da grandi pietre. Non si esclude, dunque, che queste fossero pertinenti alle pareti crollate e successivamente rimosse per compiere scavi clandestini. Mancano poi indizi certi sul tipo di copertura. Date le dimensioni del vano funerario sembra comunque doversi ipotizzare una chiusura tramite lastroni appoggiati in orizzontale. In più, l'assenza di corredo e la precaria conservazione non permettono di definirne agevolmente una datazione circostanziata, sulla base dei semplici confronti con unità sepolcrali analoghe. Tuttavia la tomba rinvenuta sembrerebbe assimilabile al tipo 1 della classificazione di Petrizzi, in relazione all'architettura funeraria costruita in ambito etrusco sui Monti della $\mathrm{Tolfa}^{73}$. A quanto pare, nei dintorni non vi sono altre evidenze archeologiche affioranti.

136 Quanto al rapporto tra il sito in oggetto e la viabilità, infine, si può affermare che la già citata carrareccia molto verosimilmente ricalca un antico tracciato romano, un percorso di crinale in direzione sudovest-nordest che in questo micro settore territoriale corre quasi parallelo al diverticolo della "Valle del Marangone $»^{74}$. La ricostruzione di siffatto percorso, che sfrutta, ove possibile accertarlo, il banco roccioso 
dei rilievi, è fattibile valutando la distribuzione degli insediamenti oggetto di nuove ricerche ${ }^{75}$.

\section{BIBLIOGRAPHIE}

Allegrezza $2004=$ V. Allegrezza, Oliveti e produzione olearia tra repubblica e principato nell'arco del Mignone : proposta interpretativa della relazione tra la villa catoniana e la fattoria a conduzione familiare, dans Bollettino Società Tarquiniese d'arte e Storia, XXXIII, 2004, p. 55-65.

Annovazzi 1879 = V. Annovazzi, Castrum Novum, dans Notizie degli scavi di antichità, 1879, p. 136.

Atlante I, 1981 = Atlante delle forme ceramiche, I. Ceramica fine romana nel bacino mediterraneo (medio e tardo impero), EAA, Rome, 1981.

Atlante II, 1985 = Atlante delle forme ceramiche, II. Ceramica fine romana nel bacino mediterraneo (tardo ellenismo e primo impero), EAA, Rome, 1985.

Bianchi - Giacomelli = A. M. Bianchi, I. Giacomelli, Santa Marinella $:$ la memoria del tempo. Le origini della città moderna attraverso le immagini, Civitavecchia, 2003, p. 77.

Bertoldi 2011 = T. Bertoldi, Ceramiche comuni dal suburbio di Roma, Rome, 2011.

Contoli et alii = L. Contoli, G. Lombardi, F. Spada, Piano per un Parco Naturale nel territorio di Allumiere e Tolfa (Lazio), Rome, 1980.

Del Lungo 1996 = S. Del Lungo, La toponomastica archeologica della Provincia di Roma, I, Rome, 1996.

Del Lungo 1999 = S. Del Lungo, Insediamenti della bassa Valle del Marta nella tarda antichità e nell'altomedioevo (secoli V-IX), dans Bollettino della Società tarquiniense di arte e storia, XXVIII, 1999, p. 23-73.

Dennis $1848=$ G. Dennis, Cities and Cemetery of Etruria, I, Londres, 1848 .

De Rossi 1971 = G. M. De Rossi, Le torri costiere del Lazio, Rome, 1971.

Desibio 2013 = L. Desibio, Le ceramiche e gli altri materiali, dans Enei et alii 2013, p. 6-7.

DOC 1 = A. R. Bellinger, Catalogue of the Byzantine Coins in the Dumbarton Oaks Collection and the Wittemore Collection, I, Anastasius I to Maurice (491-602), Washington, 1966.

Enei 2008 = F. Enei, Pyrgi Sommersa. Ricognizioni archeologiche subacquee nel porto dell'antica Caere, Santa Severa, 2008

Enei 2013 = F. Enei (dir.), Santa Severa tra leggenda e realtà storica. Pyrgi e il castello di Santa Severa alla luce delle recenti scoperte (Scavi 2003-2009), Pyrgi-Santa Severa, 2013.

Enei et alii 2011 = F. Enei, M. L. Haack, S. Nardi Combescure, G. Poccardi, Castrum Novum. Storia e archeologia di una colonia romana nel territorio di Santa Marinella, Santa Marinella, 2011 (Quaderno, 1).

Enei et alii 2012 = F. Enei, M. L. Haack, S. Nardi Combescure, G. Poccardi, Castrum Novum. Chronique des campagnes de septembre 2010 et septembre 2011, Chronique des activités archéologiques de l'École française de Rome, 2012 (http://cefr.revues.org/616). 
Enei et alii, 2013 = F. Enei, M. L. Haack, S. Nardi Combescure, G. Poccardi, Castrum Novum. Storia e archeologia di una colonia romana nel territorio di S. Marinella, Acquapendente, 2013 (Quaderno, 2).

Faudet 1999 = I. Faudet, Fibules préromaines, romaines et mérovingiennes du Musée du Louvre, [Département des Antiquités grecques, etrusques et romaines], Paris, 1999.

Fiocchi Nicolai 1988 = V. Fiocchi Nicolai, I cimiteri paleocristiani del Lazio, I, Etruria Meridionale, Cité du Vatican, 1988.

Gazzetti 1990 = G. Gazzetti, Storia del territorio in età romana, in Maffei - Nastasi 1990, p. 101-103.

Gianfrotta 1972 = P. A. Gianfrotta, Castrum Novum, Forma Italiae, Regio VII, III, Rome, 1972.

Gianfrotta 2013 = P. A. Gianfrotta, Una gemma dalla villa de «le Guardiole », in Enei et alii 2011, p. 33.

Haack et al. 2013 = M. L. Haack, S. Nardi-Combescure, G. Poccardi, F. Enei, N. André, V. Picard, Castrum Novum. Chronique de la campagne de septembre 2012 (http://cefr.revues.org/862? lang=it).

Haack 2013 = M. L. Haack, I rinvenimenti. Il materiale iscritto, in Enei et alii 2013, p. 5.

Lugli 1957 = G. Lugli, La tecnica edilizia romana con particolare riguardo a Roma e Lazio, Rome, 1957.

Maffei 1990 = A. Maffei, La ricerca topografica e la carta archeologica, in Maffei - Nastasi 1990, p. 233-239.

Maffei - Nastasi 1990 = A. Maffei, F. Nastasi (dir.), Caere e il suo territorio. Da Agylla a Centumcellae, Rome, 1990.

Marazzi 1997 = F. Marazzi, Il Patrimonium Tusciae della Chiesa romana tra VI e X secolo : note sulle sue pertinenze fondiarie, dans T.W. Potter, A.C. King (dir.), Excavations at the Mola di Monte Gelato. A roman and medieval settlement in South Etruria, Rome, 1997 (Archaeological Monographs of the British School at Rome, 11), p. 412-420.

Martorelli 1994 = R. Martorelli, Le strutture murarie di epoca altomedievale delle chiese di S. Stefano ad Anguillara Sabazia e di S. Liberato a Bracciano : analisi stratigrafica, dans Antichità tardoromane e medievali nel territorio di Bracciano (Bracciano- castello Odescalchi 15 giugno 1991), Viterbe, 1994, p. 67-96.

MIB I = W. Hahn, Moneta Imperii Byzantini, I [von Anastasius I bis Jiustinianus I (491-565)], Vienne, 1973.

Morel 1981 = J.-P. Morel, Céramique campanienne : les formes, I-II, Rome, 1981.

Morrison 1970 = C. Morrison, Catalogue des mannaie byzantines de la Bibliothèque nationale, I-II, Paris, 1970.

Nardi Combescure 2002 = S. Nardi Combescure, Paesaggi d'Etruria Meridionale. L'entroterra di Civitavecchia dal II al XV secolo d. C., Florence, 2002.

Nardi Combescure 2013 = S. Nardi Combescure, Castrum Novum : le nuove indagini, dans Enei et alii 2013, pp. 2-3.

Olcese $2003=\mathrm{G}$. Olcese, Ceramiche comuni a Roma e in area romana : produzione, circolazione e tecnologia : tarda età repubblicana-prima età imperiale, Mantoue, 2003.

Ortolani 1994 = G. Ortolani, Aspetti costruttivi in chiese medievali del territorio di Bracciano. Richiami e sopravvivenze dall'antico, dans Antichità tardoromane e medievali nel territorio di Bracciano (Braccianocastello Odescalchi 15 giugno 1991), Viterbe, 1994, p. 99-124. 
Oxé 2000 = A. Oxé, H. Comfort, Corpus Vasorum Arretinorum. A catalogue of the Signatures, shapes and Chronology of Italian Sigillata, Bonn, 2000.

Petrizzi $1990=$ C. V. Petrizzi, La diffusione delle tombe costruite sui Monti della Tolfa, in Maffei Nastasi 1990, p. 76-82.

Squaglia 2013 = A. Squaglia, I Santi perduti di Castrum Novum, in Enei et alii, p. 68-71.

Steinby 1978 = M. Steinby, Lateres signati ostienses, Rome, 1978.

Stracci 2013 = G. Stracci, I materiali lapidei da costruzione, in Enei et alii 2013, p. 13-14.

Tortorella 1981 = S. Tortorella, Ceramica Africana, Ceramica da cucina, in Atlante I, 1981, p. 208-224.

Toti 1996 = O. Toti, Storia di Civitavecchia, II, Ronciglione, 1996.

Volpe $2005=\mathrm{G}$. Volpe, Villaggi e insediamento sparso in Italia meridionale fra tardo antico e alto medioevo : alcune note, dans G. P. Brogiolo, A. Chavarria Arnau, M. Valenti (dir.), Dopo la fine delle ville : le campagne dal VI al IX secolo, Mantoue, 2005 (Documenti di Archeologia, 40), p. 221-249.

\section{NOTES}

1. Dennis 1848, I, p. 295, ripreso in Del Lungo 1996, I, p. 269.

2. De Rossi 1971, p. 37-38. Cfr. oltre il contributo di A. Squaglia.

3. Archivio di Stato di Roma, Presidenza delle Strade, Catasto Alessandrino, 428/15,15 marzo 1660 e Archivio di Stato di Roma, Catasto Rustico della Provincia di Roma, Civitavecchia LXXVI, tenute : Santa Marinella.

4. Si tratta di un'operazione di scavo di salvataggio che fu effettuata all'epoca della costruzione delle villette a nord dell'area dello scavo. Stando a quanto riportato da alcuni degli abitanti del comprensorio, l'area del balneum fu utilizzata come zona di accumulo di terra durante i lavori di costruzione della piscina. Dall'immagine riportata alla figura 1, si può avere un'idea dell'area de «le Guardiole ", nei decenni anteriori il grosso sviluppo urbanistico di questa zona, avvenuto durante gli anni '60-'70 del secolo scorso.

5. Gianfrotta 1972, p. 326-338. Si rimanda anche a Enei et alii 2011, Enei et alii 2012, Haack et alii 2013.

6. CIL XV, 2, 133 e CIL XV, 1, 2163.

7. Gianfrotta 2013, p. 33.

8. Gianfrotta 1972, p. 336-338.

9. Le indagini dell'équipe francese di Castrum Novum sono state possibile grazie al sostegno economico ed all'interesse della Soprintendenza per i Beni archeologici dell'Etruria meridionale, dei centri di ricerca CRAE (Université de Picardie, UFR ARTS), TRAME (Université de Picardie, UFR HISTOIRE ET GEOGRAPHIE), HALMA-IPEL (Université de Lille III) dell'équipe AOROC (ENSCNRS) e del Comune di Santa Marinella. Si coglie quindi l'occasione per ringraziare la Soprintendente Alfonsina Russo, l'ispettrice di zona Rossella Zaccagnini, i colleghi Lorenzo Vinciguerra, Christophe Bident, Marie-Domitille Porcheron, Stéphane Verger, Loriane Sève, Kathérine Gruel, il sindaco di Santa Marinella Roberto Bacheca, i membri dell'associazione Yacht Club di Santa Marinella, in particolare Claudio e Fiorella Caneva, i membri dell'Associazione dei Pescatori Sportivi di Santa Marinella, Claudio Biagioli e Fausta Bachetti. Ai lavori condotti nelle zone A e B hanno partecipato, oltre agli autori di questi contributi: Alice Bourgeois, Arnaud Deigre, Benjamin Paris, Simon-Pierre Mattei, Anaïs Joly, Marine Leroy, Nicolas Duhaut, Michel Athanassiadis e Naouel Amrani. La documentazione grafica è stata curata da Nathalie André e Véronique Picard (IRAA-USR 3155 del CNRS, Université de Pau et du Pays d'Adour). Ne approfittiamo per segnalare un piccolo errore nel contributo precedente (Haack et alii 2013) dove 
la ceramica del balneum delle Guardiole è stata in realtà studiata da Luca Desibio mentre quella dell'edificio quadrato da Francesco Massimi.

10. Gianfrotta 1972, p. 100, fig. 218.

11. Gianfrotta 1972, p. 102, fig. 218.

12. Gianfrotta 1972, p. 113, fig. 238, cfr. oltre relazione di F. Enei.

13. Gianfrotta 1972, p. 93, fig. 197, cfr. oltre relazione di M. L. Haack.

14. Annovazzi 1879; cfr. oltre relazione di Marie Laurence Haack.

15. Per i bolli ritrovati nei vasi in sigillata italica, cfr. oltre relazione di Marie Laurence Haack.

16. Faudet 1999, p. 52. Per la bibliografia si rimanda allo stesso autore.

17. Cfr. oltre relazione seguente di M. L. Haack.

18. Répertoriés dans Oxé 2000, p. 262, nº 1036.

19. Nous remercions $C$. Bruun pour son aide à la lecture et à l'interprétation de l'inscription.

20. Enei et alii, 2011.

21. Gianfrotta 1972.

22. Ringrazio Sara Nardi Combescure per il lavoro affidatomi nell'ambito del progetto di ricerca Castrum Novum e gli amici e colleghi Massimiliano Galletti e Massimo Vitti per i consigli e i suggerimenti. Preciso che sono in corso ulteriori approfondimenti delle unità stratigrafiche murarie e che le presenti note costituiscono per il momento una breve analisi preliminare dei dati a disposizione.

23. Gianfrotta 1972, pp.100-110.

24. Gli ambienti indagati negli ultimi anni sono indicati nelle relazioni di scavo 2010-2013 sono indicati dai nn. 1-7 (Nardi Combescure 2013, p. 3).

25. Gianfrotta 1972, p.99-100. Al contrario le ultime acquisizioni di natura topografica sull'insediamento romano hanno evidenziato l'assenza di qualsiasi coerenza di orientamento tra le strutture rilevate nel settore indagato e quelle presenti sulla costa (Nardi-Combescure 2013, p. 3).

26. Gianfrotta 1972, p. 102.

27. Ibidem.

28. I materiali recuperati all'interno della terra di riempimento del condotto (US 116) sono costituiti da tessere musive, frammenti ceramici, tra cui l'ansa di un'anfora del tipo Forlimpopoli e Pelichet 47. I dati riportati sono parziali ma ci consentono di stabilire un terminus post quem non per la datazione dei reperti al III secolo d. C.

29. Haack 2013, p. 5.

30. Il muro 5 , in opera cementizia con paramento in pezzame di pietra di piccole e medie dimensioni apparecchiate per filari orizzontali, potrebbe essere assimilato ad un opus vittatum semplice, cioè composto di sola pietra, diffuso nel Lazio a partire dall'età adrianea fino alla fine del III secolo (Lugli 1957, p. 634). Questo tipo di muratura in piccoli blocchi di pietra calcarea locale è impiegata nelle murature perimetrali dell'intera struttura. In particolare sui materiali lapidei utilizzati nelle strutture del balneum vedi Stracci 2013, pp.13-14.

31. Gianfrotta 1972, p. 102, Nardi Combescure 2013, p. 2.

32. Gianfrotta1972, p. 104.

33. Nardi Combescure 2013, p. 2. In realtà l'irregolarità della parte superiore del paramento dei muri 8 e 9, potrebbe suggerire un rifacimento di epoca medievale ispirato dalla tradizione antica realizzato mediante il reimpiego di pezzame di pietra locale della struttura romana. In particolare da segnalare il paramento della facciata della Chiesa di S. Caterina a Trevignano Romano, in cui il riutilizzo di cubilia ha dato origine ad un «disordinato " ma decorativo opus reticulatum (Ortolani1994, pp. 99-124). Inoltre da segnalare la presenza di un blocco di scaglia riutilizzato nel paramento del muro 8 unitamente all'utilizzo di « tufelli » in pietra locale.

34. Ibidem.

Chronique des activités archéologiques de l'École française de Rome , Italie centrale 
35. In questo caso la cronologia formulata da Gianfrotta andrebbe rivista collocando la prima fase di vita dell'impianto nel I-II secolo d. C. e una seconda fase, coincidente con la ristrutturazione del balneum, nel III secolo d. C.

36. In tal caso la funzione degli ambienti riscaldati andrebbe invertita: A7 tepidarium e A3 caldarium del nuovo impianto termale.

37. Gianfrotta 1972, p. 104-105, Nardi Combescure 2013, p. 2.

38. Gianfrotta 1972, p. 106.

39. Idem, p.106, nota 1: « i materiali comunque non sono ancora stati studiati ed è probabile che a studio ultimato la datazione proposta possa essere soggetta a leggere variazioni ».

40. In particolare il ritrovamento di ceramica africana da cucina "a patina cenerognola" potrebbe abbassare la cronologia della frequentazione del sito al IV secolo d. C. (cfr. Desibio 2013, pp. 6-7). Sullo studio preliminare dei reperti vedi: Enei et alii, 2013, pp. 5-12.

41. Nardi Combescure 2013, p. 2-3.

42. Eadem.

43. La muratura presenta spiccate assonanze con fortificazioni altomedievali : http:// www.provincia.bergamo.it/provpordocs/cap_4_2_All_1_sch05.pdf; per le caratteristiche murarie ascrivibili ad epoca altomedievale cfr. Martorelli 1994, p. 67-96 e Volpe 2005, p. 221-237.

44. Fiocchi Nicolai 1988, pp.7-15. Sul problema della trasformazione strutturale dell'organizzazione territoriale in Etruria Meridionale in epoca tardoantica si rimanda a Marazzi 1997, pp. 412-420 e Del Lungo 1999, pp. 23-73.

45. Nardi Combescure 2013, p. 3. La conformazione triangolare della struttura addossata al muro perimetrale del balneum potrebbe evocare una ipotetica torre a sperone, di tipo bizantino, tipologia difensiva riscontrata, durante le guerre greco-gotiche anche a Centumcellae, come evidenziato da uno schizzo di Antonio Sangallo (cfr. Toti 1996, p. 44).

46. Gianfrotta 1972, p. 115.

47. Per gli scavi degli anni '70 si rimanda a Gianfrotta 1972, p. 115-117.

48. Foto in Gianfrotta 1972, p. 116, fig. 245.

49. Gianfrotta 1972, p. 115, fig. 243.

50. Gianfrotta 1972, p. 115, fig. 242.

51. Gianfrotta 1972, p. 113, fig. 238, 239, p. 114, figg. 240, 241, p. 116.

52. Gianfrotta 1972, p. 117, fig. 250.

53. Olcese 2003, tav. XX, p. 89.

54. Atlante I, 1981.

55. Enei et alii, 2013, p. 28-29

56. Morel 1981, pl. 87, p. 249.

57. Morel 1981, pl. 47, pp. 164-165.

58. Atlante II, 1985.

59. Atlante I, 1981.

60. Comune di Santa Marinella, ubicazione: IGM F 142 , II, SE, UTM32TQM371618.

61. Desidero ringraziare Sara Nardi Combescure per l'attenzione dimostrata. Un ringraziamento particolare anche a Flavio Enei, Giulio Rinaldi e Alessandra Squaglia per gli utili suggerimenti fornitomi.

62. Si rimanda a Gianfrotta 1972 con relativa bibliografia.

63. Per un inquadramento geomorfologico e petrografico della zona cfr. Contoli et alii 1980.

64. Sugli impianti produttivi delle ville rustiche romane scoperte nel territorio di Civitavecchia rinvio a Maffei 1990, p. 233-239, cfr. anche Allegrezza 2004, p. 59 s.

65. Nell'area dei Monti della Tolfa la storia del popolamento nel periodo romano è condensata in Gazzetti 1990, p. 101-103.

66. Si tratta di una situazione già riscontrata o ipotizzata in alcuni siti romani nell'Arco del Mignone. A tal proposito si veda ad esempio Maffei 1990, p. 236. 
67. Sulla base del confronto con esemplari monetali analoghi è verosimile ipotizzare la seguente integrazione: [DN] IUSTINIANUS [PPAVC], cfr. DOC I, pp. 178-179. 331.1-331.13, MIB I, 228, Morrison 1970, 4/Ro/AE/27-35.

68. La riforma monetaria bizantina introdotta dall'imperatore Anastasio I nel $498 \mathrm{~d}$. C., prevedeva che nella maggior parte delle monete in bronzo vi fosse indicato il valore con la numerazione greca. Pertanto I = 10 (decanummo = 10 nummi).

69. Per quanto attiene la datazione la moneta potrebbe essere assegnata alle emissioni del 547-549 (MIB I, 228), e del 547-565 (DOC I, pp. 178-179. 331.1-331.13.

70. Procopio di Cesarea, Bellum Gothicum, II, 7; III, 13, 37, 39; IV, 34.

71. Circa il ruolo assunto da Centumcellae nel corso del conflitto greco-gotico, e le conseguenze delle vicende belliche sulla popolazione rurale si rimanda a Nardi Combescure 2002, p. 79 ss. Quanto all'assetto delle diocesi tra V e VI secolo soprattutto in riferimento al culto dei martiri tradizionalmente attribuito al territorio di Castrum Novum si veda Squaglia 2013, pp. 68-71, in particolare la nota 17 a p. 69.

72. Enei 2008, p. 48 e pp. 100-101.

73. Così viene descritto il tipo 1 (Petrizzi 1990, p. 82) : « Ambiente ristretto, completamente chiuso, di pianta rettangolare, con pareti realizzate con pochi filari di pietrame locale, inclinate all'interno a sezione trapezoidale e coperto, in origine, molto probabilmente da lastroni. Un tumulo ricopriva l'intera struttura (tomba a cassone) ».

74. Tale diverticolo si distaccava all'altezza dell'attuale km 67 della Via Aurelia (Gianfrotta 1972, p. 133).

75. Si tratta di insediamenti testimoniati principalmente da ristrette aree di frammenti fittili, individuati dallo scrivente e ancora inediti.

INDEX

institutions AOROC (UMR 8546 CNRS-ENS), Université de Picardie Jules Verne, Université Lille 3 (HALMA-IPEL - UMR 8164), TRAME, Soprintendenza archeologica per i Beni archeologici dell'Etruria meridionale, Museo civico di Santa Marinella

Mots-clés : colonie romaine maritime, balneum, Étrurie, Caere, Cerveteri, Santa Marinella

Index géographique : Castrum Novum, Santa Marinella

\section{AUTEURS}

\section{FLAVIO ENEI}

Museo del mare e della navigazione antica, Santa Marinella

\section{MARIE-LAURENCE HAACK}

AOROC (UMR 8546 CNRS-ENS), Université de Picardie Jules Verne, TRAME - haackml[at]yahoo.fr

\section{SARA NARDI-COMBESCURE}

Université de Picardie Jules Verne, AOROC (UMR 8546 CNRS-ENS) - saracombescure[at]free.fr 


\section{GRÉGOIRE POCCARDI}

Université Lille 3 (HALMA-IPEL - UMR 8164) - gregoire.poccardi[at]univ-lille3.fr

\section{LUCA DESIBIO}

Université degli studi di Roma 3, Gruppo Archeologico del Territorio Cerite

\section{MASSIMILIANO GALLETTI}

Museo del mare e della navigazione antica, Santa Marinella

\section{ALESSANDRA SQUAGLIA}

Museo del mare e della navigazione antica, Santa Marinella

DAVID VATTIER

Service d'archéologie d'Amiens Métropole, Centre de recherche en arts et esthétique 